Portland State University

PDXScholar

Spring 7-24-2013

\title{
The Economic Impact of Veteran Status: The Effect of Veteran and Demographic Statuses on Household Income
}

Daniel Standridge

Portland State University

Follow this and additional works at: https://pdxscholar.library.pdx.edu/open_access_etds

Part of the Educational Sociology Commons, Gender and Sexuality Commons, Race and Ethnicity Commons, and the Work, Economy and Organizations Commons Let us know how access to this document benefits you.

\section{Recommended Citation}

Standridge, Daniel, "The Economic Impact of Veteran Status: The Effect of Veteran and Demographic Statuses on Household Income" (2013). Dissertations and Theses. Paper 977.

https://doi.org/10.15760/etd.977

This Thesis is brought to you for free and open access. It has been accepted for inclusion in Dissertations and Theses by an authorized administrator of PDXScholar. Please contact us if we can make this document more accessible: pdxscholar@pdx.edu. 
The Economic Impact of Veteran Status: The Effect of Veteran and Demographic

Statuses on Household Income

by

Daniel Standridge

A thesis submitted in partial fulfillment of the requirements for the degree of

Master of Science

in

Sociology

Thesis Committee:

Matthew Carlson, Chair

Melissa Thompson

Hyeyoung Woo

Portland State University

2013 
(C) 2013 Daniel Standridge 


\section{Abstract}

Determining the effects of military service on those who volunteer is of vital importance in an age when service may lead to the loss of bodily function or life. The aim of this study was to examine the effect of military service with consideration for the demographic statuses of race, gender, and educational attainment on economic outcomes. Data for this study came from the Current Population Survey July 2010 with Veterans Supplement $(\mathrm{N}=83,000)$. Results from this study suggest that some veterans, namely those of minority racial status and lower educational attainment benefit from their military serve by achieving increased levels of household income as compared to similar non-veterans. Conversely, non-Hispanic White veterans and those with higher levels of educational attainment suffer negative consequences to levels of household income. These results provide further insight into the experiences of veterans in the United States. 


\section{Acknowledgments}

I thank the members of my thesis committee Dr. Matthew Carlson, Dr. Melissa Thompson, and Dr. Hyeyoung Woo for their participation within this project and their helpful yet critical feedback throughout the process. I thank Dr. Carlson, my advisor, for paying special attention to my writing to ensure the highest quality. Further thanks go to Drs. Woo and Thompson for paying attention to my research methods, a process which is never ending and vital.

I thank my friends in the department, my family, and those outside of academia, who listened to me process through the writing and providing regular support and feedback and spent hours being that second, or third, or fourth pair of eyes looking over my work. Especially Kym, Jeff, and Patrick; they encouraged me to recognize my own strengths and abilities and picked me up on those hard days.

Most importantly, I want to give my thanks to JaNae for being a wonderful partner who has ceaselessly supported me throughout this process. Without you this research would have been severely weakened or remained incomplete. JaNae, thank you for helping me shoulder this burden. 


\section{Contents}

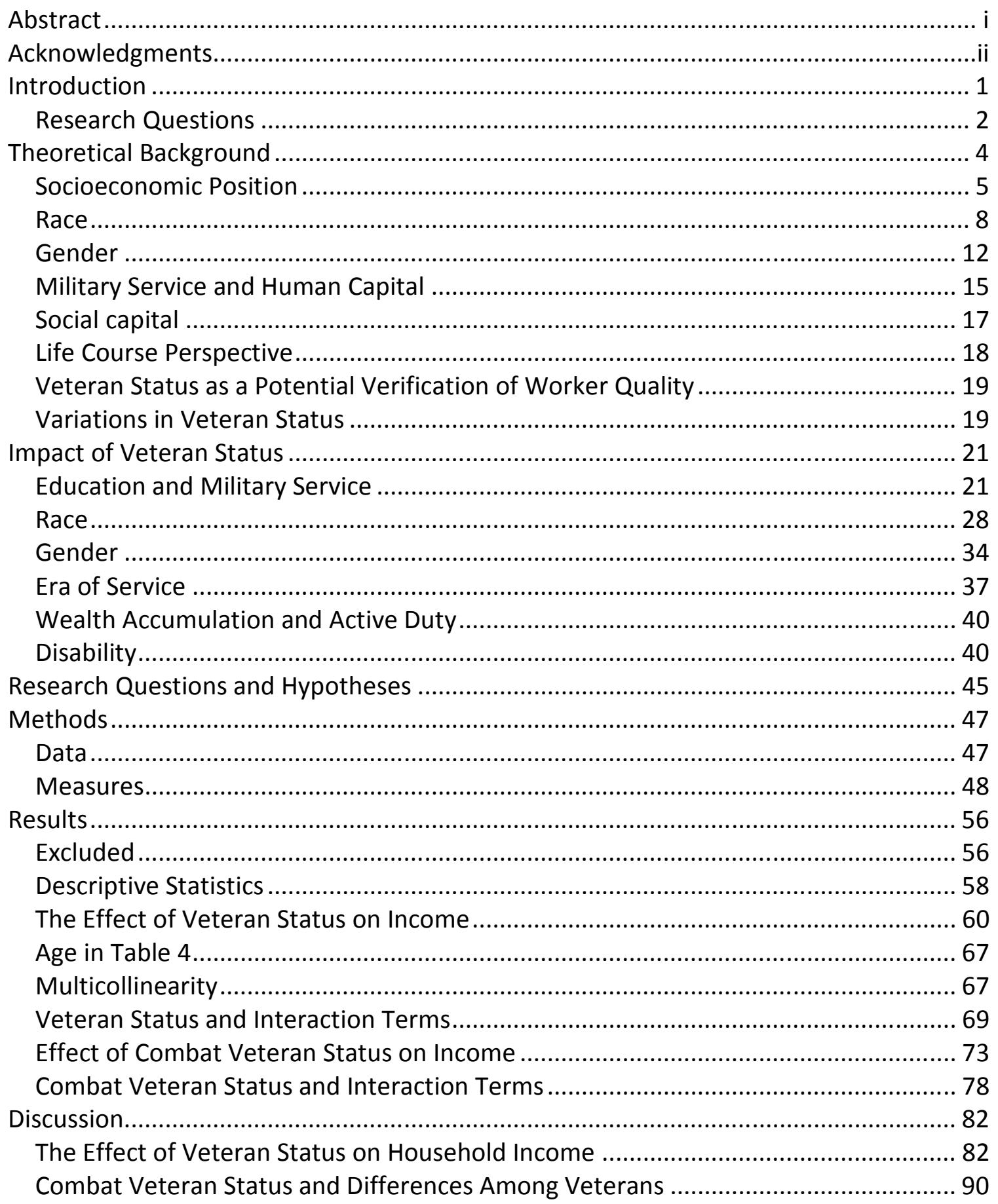




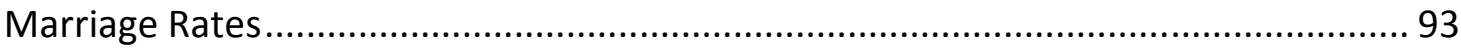

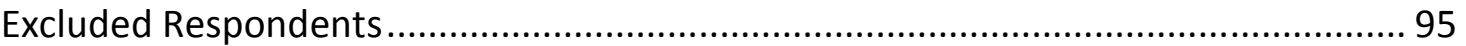

Occupation Sector, Veteran Status, and Demographics........................................... 96

Occupation Sector, Combat Veteran Status, and Demographics............................... 99

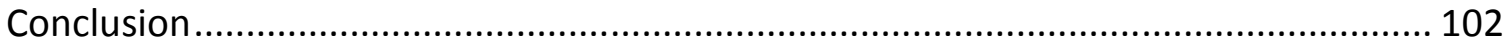

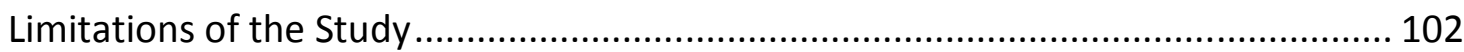

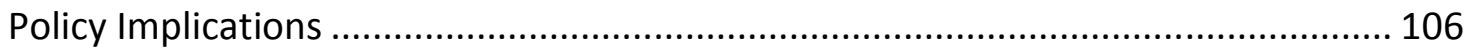

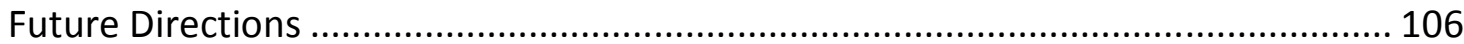

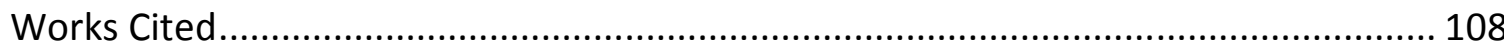

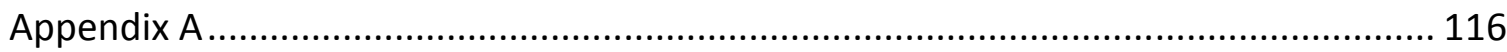

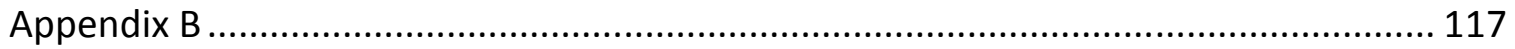




\section{List of Tables}

Table 1: Household Income Categories...........................................................................50

Table 2a: Descriptive Statistics of Included and Excluded Respondents........................56

Table 2b: Descriptive Statistics of Sample...................................................................58

Table 3: Descriptive Statistics of Veterans..................................................................59

Table 4: OLS Regression of Household Income on Veteran Status...............................62

Table 5: OLS Regression of Household Income on Veteran Status with Interaction

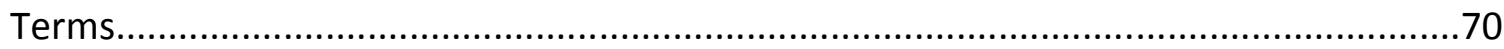

Table 6: OLS Regression of Household Income on Combat Veteran Status.....................74

Table 7: OLS Regression of Household Income on Combat Veteran Status with

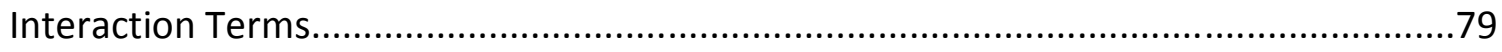

Table 8: Descriptive Statistics of Unmarried Respondents.......................................93 


\section{List of Figures}

Figure 1: Impact of Race and Veteran Status on Household Income.........................84

Figure 2: Impact of Veteran Status and Educational Attainment on household

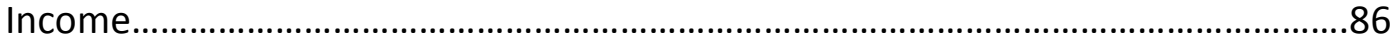




\section{Introduction}

According to the Bureau of Labor and Statistics (BLS) 20.2 million men and 1.8 million women over the age of 18 in United States are considered veterans in the United States (2011). Due to the conflicts of Operation Iraqi Freedom (OIF) and Operation Enduring Freedom (OEF) in Afghanistan, there has been a surge of younger men and women into the aging veteran population. According to the BLS 2.2 million veterans have served in the conflicts since 2001 (2011:2). With nearly two-thirds of these recent veterans being under the age of 35 (BLS 2011:2), many veterans are expected to participate in the civilian economy for years to come.

Veterans face unique difficulties that may interfere with their ability to participate in the workforce. Because of advanced medical care, troops are more likely to survive wounds that in the past would have been fatal (Belmont, Schoenfeld, and Goodman 2010). As a result, more troops are returning from war having survived or experienced both physical and mental traumatic events. These traumatic experiences may place combat veterans at a disadvantage in navigating the civilian workforce as compared to their civilian counterparts. Conversely combat veterans may receive financial advantages in the form of more readily available acceptance by the VA as compared to other veterans and non-veterans.

As this research will show, those who serve in the military tend to be from economically disadvantaged groups (Cohen, Segal, and Temme 1986; Cohen, Warner, 
and Segal 1995; MacLean 2005). Those who serve in the military may receive access to human capital, skills and behaviors, in the form of training (Kleykamp 2009; Cooney et al. 2003; Hope, Oh, and Mackin 2011; Teachman and Tedrow 2007), experience (Teachman and Tedrow 2007), educational benefits (Cooney et al. 2003; Hope, Oh, and Mackin 2011) and social capital, relationships which positively impact economic performance and from which it is possible mentorship is received. Further research is warranted not only due to the limited availability of current knowledge, but also due to the increasing numbers of veterans expected to return from the OIF and OEF conflicts. Identifying possible advantages and disadvantages that veterans face will be particularly important as unemployment rates for all those in the United States reach record highs.

Although previous research has been done to analyze the economic performance of veterans, the current study uses the 2010 Current Population Survey which will provide a more recent picture of veteran economic performance. This project will attempt to discern the level at which veterans are performing within the economy, specifically with concern to household income. Furthermore this project will attempt to illuminate differences, if they exist, in economic wellbeing across race, gender, age, and educational groups among veterans and non-veterans.

\section{Research Questions}

The purpose of this research is to address the following research questions:

- How does veteran status affect household income? 
- How does the affect of veteran status on household income differ by race?

- How does the affect of veteran status on household income differ by gender?

- How does the affect of veteran status on household income differ by educational attainment?

- What effect does combat status have on household income among veterans? 


\section{Theoretical Background}

The central theoretical focus of this project concerns the importance of varying forms of capital (human, social, etc.) for determining economic outcomes and whether they are obtained or missed as a result of military service. Whether capital comes in the form of human capital or social capital, it serves to alter the economic performance of workers and the value applied to them by employers. Existing research suggests that the military provides human and social capital in the form of skills, credentials, and networking opportunities that alter the subsequent economic performance of veterans and the way they are valued by employers. Research also shows that military service negatively impacts veterans' economic outcomes due to decreased levels of participation in the civilian labor force.

In this chapter I describe the negative effects of socially disadvantaged statuses on economic performance for women, racial minorities, and those with lower education as compared to their more advantaged counterparts. While overt discrimination may have subsided in our society, its consequences still remain salient for many. It is possible that service in the military will act to provide access to human and social capital that would have otherwise been missed by those who do not serve. The military may also provide an egalitarian environment in which those previously disadvantaged are provided with strong mentors, training, experience, and later educational benefits 
which help them to out-perform their non-veteran peers. First an understanding of the effects of carrying a socially disadvantaged status will be discussed.

\section{Socioeconomic Position}

To understand the socioeconomic status of a person, an understanding of class is necessary. Wright (1997) provides a general overview of the primary class locations which are: the Capitalist, the Petty Bourgeoisie, the skilled labor, managers, non-skilled labor, and the underclass. Each position is associated with differing levels of ownership and authority which directly impacts their economic wellbeing. The process of exploitation, a tenet central to the understanding of inequality within a society, allows for the identification of the primary classes in a capitalist society; class location is intimately tied to the level of exploitation experienced. The capitalist class exploits the efforts of the working and middle class; some of the exploited or surplus wages go to the middle class to ensure their loyalty. Thus the exploitation of the wages of the working and middle classes by the capitalists works to create and reinforce income inequalities (Wright 2005). While many other class analysis lenses exist, Wright (1996) argues that the conceptual understanding of exploitation is what separates Marxist analyses apart from stratification, Weberian based, or other forms of class analysis. The argument over class becomes more than simply differences over skill acquisition, but includes the understanding that one group systematically works to deny another group access to resources. 
According to Wright (1997) a person's class location limits their consciousness or the availability of certain mindsets. This means that the location of a person's class, which is measured by their occupation, educational credentials, ownership status, etc., directly affects the types of practices and behaviors available to them. Class location further limits the choices and practices of the individual; the working class person has a limited availability of choices to generate income as compared to the capitalist who has a broader selection to choose from (Wright 1997:390). Those within the Capitalist class may have unimpeded access to these resources; those belonging to the working class may have limited access to sources of capital let alone differing methods of attaining them. The economic success a person may experience is therefore partly reliant on factors that precede their participation in the labor market because of these limitations brought about by class location.

According to Blau, Brinton, and Grusky (2006) wages affect but do not necessarily lead to economic wellbeing. Blau et al. (2006) state that wages are correlated with positive workplace experiences such as status, working conditions, and benefits. Furthermore, Blau et al. (2006) state that, in the home, wages factor in the decision making process; if a wage disparity exists in the home then there is likely to be unequal bargaining power which negatively effects the person who earns lower wages. Lastly, Blau et al. (2006) state that assuming equal performance by all workers, any 
wage disparity illuminates existing inequalities. If an inequality exists which leads to a wage disparity, there is a need for change to allow for equal opportunities for all.

Class differences are a necessary component of capitalism. It is possible that social stratification in the economic sphere is necessary since it may motivate people to achieve higher positions and to perform the duties of a particular position well (Davis and Moore 1945; Kreuger 2003). There must exist some form of reward to ensure that tasks vital to society which may be difficult, undesirable, or hard to fill are completed (Davis and Moore 1945). These increased rewards ensure that those positions which are not as necessary or are easily filled do not readily compete with the jobs which are deemed necessary (Davis and Moore 1945). This resulting wage inequality ideally ensures efficient behavior within an economic system. Furthermore, because rewards are determined by societal need, the resulting inequality is also socially constructed (Fischer, Hout, Jankowski, Lucas, Swidler, and Voss 1996). It is when this inequality results from non-productivity related measures, such as race, that stratification becomes inefficient (Kreuger 2003).

The theories introduced in this section detail the effect that socioeconomic position has on the individual. As Wright (1997) points out, those in lower tiers of society are faced with a decreased access to human and social capital and face difficulties in accessing these same capitals. It may be the case that veteran status allows for an increased availability of and a greater access to forms of capital. While it is 
unlikely that military service will allow most veterans to achieve great levels of wealth and economic success, it may provide access to privilege which typically may lower levels of exploitation due to skill and loyalty rents (Wright 1997). If in fact the military does allow for greater access to forms of capital, either through skills training, instilling of positive labor related characteristics, or creation of relationships all of which may lead to greater economic performance, the positive effect of greater wages as explained by Blau et al. (2006) will work to improve the overall quality of life for veterans. It may be the case that service in the military will work to decrease the presence of economic disparities that exist within the United States.

\section{Race}

Omi and Winant (1994) state that race is a non-biological, social and historical process which symbolizes social conflict through the emphasis on bodily differences. Because race is a social process, society ascribes attributes to people which we act upon unconsciously (Omi and Winant 1994). Therefore it is impossible and incorrect to deny the existence or impact of race. The following arguments center around the impacts of race among White and Black Americans, however it is assumed that existing outside of the dominant preferred group will bring with it similar experiences to those of Black Americans.

The United States has a long history of racism between its privileged White and underprivileged minorities; this discussion focuses on the contention between White 
and Black labor, but assumes that all racial minorities experience similar disadvantages. As a result of racist practices spurred by increased economic competition, Black labor was devalued which led to lower paying, less skill dependent occupations (Wilson 1978). Because of the devaluing of Black labor in the industrial era, competition with White labor decreased, thus decreasing the need for overt racist behaviors (Wilson 1978). In the place of overt racism, the United States' society is left with a devalued Black labor force that has low economic and social power (Wilson 1978; Wright 1979).

Wilson states that the goal of capitalism is to increase profits; this must be done in competition with workers who desire to increase wages (1978). In order to suppress worker demands, the capitalist class has a desire to promote divisions among the working class. When a group of people is devalued, there exists the opportunity for capitalists to combat a strong labor movement; furthermore the existence of a devalued group allows for the further exploitation of surplus due to lower labor costs (Wilson 1978).

In the United States White labor is afforded preferential treatment over Black labor (Cohn 2000) due to discriminatory practices and unequal access to forms of capital. While Blacks' wages have increased over time, they continue to be lower than the wages of Whites'. This wage gap cannot solely be explained by different skill levels due to the diminishing educational attainment gap for high school and to a much lesser extent college (Cohn 2000). This suggests that the wage differential that exists due to 
race is not only about players being deficient in human capital but that there are more factors such as the various forms of capital, and perhaps status appeal involved.

While the devaluation of Black labor has led to decreased wages and wealth, there also exists a long history of poor educational opportunities for Black Americans (Meier, Stewart, and England 1989). Gamoran (2001) states that while high school education attainment rates for Blacks and Whites are relatively similar, college attainment rates differ drastically citing research showing Bachelor's degree attainment rates of $27.5 \%$ for Whites and only $12.2 \%$ for Blacks. Since college attendance rates remain lower for Black Americans, higher paying occupations remain out of reach. Wright (1979) adds that Black males receive fewer returns from their education as compared to White males; this indicates that controlling for educational levels, White males earn a wage premium. Thus, the increasing importance on capital obtained from a post-secondary education adversely impacts Black and perhaps other minority labor. Income is defined as the amount of money a person obtains over time and wealth refers to what a person owns and what opportunities that ownership provides for further success (Oliver and Shapiro 1997). Past governmental actions have been used to severely limit the wealth building opportunities of Black and minorities populations in the United States (Oliver and Shapiro 1997). This coupled with living in poverty due to economic devaluation by employers and workers has led to a decrease in wealth building opportunities for Black Americans (Oliver and Shapiro 1997). 
Residential segregation, a practice which has disproportionally affected Black Americans, leads to limited access to education, capital, and other vital benefits which further decreases opportunities to escape such problems (Massey and Denton 1993). This denial of access to economic, cultural, and social resources has severely limited the opportunities available to minority populations. Furthermore, in segregated neighborhoods that are associated with poverty, decisions that lead to disinvestment in the community quickly lead to disinvestment by others (Massey and Denton 1993.

The history of the United States is typified by racist actions of varying degrees in an ultimate effort to disproportionately benefit economically the dominant group in society. Since race is socially constructed, its meaning and consequent understanding is inherent to all people within a society. These discriminatory practices have limited the economic performance of racial minorities. Race limits class location (Wright 1979), educational quality and attainment (Meier et al. 1989; Gamoran 2001), wealth generation (Oliver and Shapiro 1997), and opportunities through segregation (Massey and Denton 1993). It may be the case that service in the military removes people from disadvantaged environments and provides them with the opportunity to overcome these negative effects of racist practices. The military, being one of the largest employers in the United States, is more likely to have lower levels of discriminatory practices as explained by Cohn (2000). 


\section{Gender}

Within society, gender is used to create difference, categories where one is valued over another; gender is used as a way of assigning roles, responsibilities, and rights and to justify inconsistent treatment between the two gender categories (Lorber 1994). Occupations typed as "male work" tend to be valued greater than those typed as "female work" (Hochschild 1997; Lorber 1994). Gender roles place females as nurturers and interpersonally skilled while males are seen as excelling at interacting with the physical world (Charles and Grusky 2004). Because of the beliefs in gender roles and male primacy, employers may value male labor over that of females (Charles and Grusky 2004). Furthermore, the existence of gendered jobs causes a glut of female labor forcing competition for a limited sector of the economy; this occurs while males compete for a wider selection of occupations that are seen as male "appropriate" (Cohn 2000). Because of increased levels of demand for a limited supply, wages can be depressed for female labor by employers. Due to preferential treatment, the more opportunities and resources exist, the more they tend to be controlled by the male gender thus leading to a decrease in power, prestige, and economic rewards for the female gender (Lorber 1994).

Due to traditional gender roles, historically women have had decreased levels of participation in the labor force which led to a decreased incentive to seek out labor skills (Blau and Kahn 2006); traditional gender roles led to a decreased desire to invest in 
human, social and other forms of capital relevant to the labor force (Cohn 2000). Women may continue to avoid occupations that require extensive skills and employers may be hesitant to provide skill training necessary to female workers (Blau and Kahn 2006). This lower skill attainment, according to the human capital theory, leads employers to devalue female labor and to pay lower wages (Cohn 2000). The wage differential across gender may be due to discrimination based on personal tastes, statistical discrimination, and overcrowding of female labor in the limited female “appropriate" occupations (Blau and Kahn 2006).

Employers prefer to hire labor with relevant skills (Cohn 2000) and thus the amount of training a worker has determines their earning potential (Polachek 2006). To obtain these skills, both employees and the firm must invest in training (Cohn 2000). Because of gendered expectations, it is argued that women are less likely to invest in firm general skills, those skills workers are expected to obtain on their own that apply to most occupations, and employers are less willing to invest in firm specific skills for female employees (Cohn 2000). Decreased labor force participation is equated with decreased levels of relevant skills; this may lead to on average depressed female earnings as compared to male labor due to decreased labor force participation (Polachek 2006). The major problem with this theory is that it does not account for the existence of female and male occupations. Gendered occupations exist in such fields as 
nursing, elementary teaching, etc.; these female occupations are not filled with "quit prone" women and in fact mirror the labor behaviors of male occupations (Cohn 2000).

Reskin (1991) adds the concept of the queuing perspective which states that the level of preferential ideology held by employers and workers, mixed with the availability of labor or jobs can influence the possibility of discriminatory behaviors. To the extent that a labor market is saturated with available workers, employers will be able to exercise discriminatory or unequal hiring practices based on their tastes. Conversely, markets saturated with jobs leave the employer with a decreased ability to exercise discriminatory hiring practices based on their personal tastes due to a lack of available labor.

Since the 1930s women's relative earnings have increased, the type of work they perform has changed, and the education gap has nearly vanished (Blau and Kahn 2006). The fact that the education gap has closed should work to discredit the argument that women are deficient in human capital. Furthermore, women have an increasing presence in male occupations and they are more likely to remain in the labor force for extended periods of time as males have traditionally (Blau and Kahn 2006) which may further increase levels of human and social capital. Still, women have on average less work experience (Blau and Kahn 2006), which may negatively impact wages earned.

In this section the impact of male and female typed occupations was introduced. The presence of these occupations not only decreases the availability of jobs for female 
labor, but also allows for a devaluing of female typed occupations based on discriminatory beliefs. This, coupled with gendered labor practices which not only limit participation but also skill acquisition, leads to lower wages for female labor. It may be the case that service in the military provides access to firm relevant skills and perhaps decreases the inhibition of occupational choices based on gendered norms. The increased access to experience and skills may lead to an increased availability of job opportunities and wages. Furthermore, joining occupations outside of the gendered norm may allow for increased opportunities and the ability to circumvent the labor glut which decreases wages often found in female-typed occupations. Ultimately, the military may provide some form of benefit which helps women to overcome the apparent economic disparities they face in the United States labor market.

\section{Military Service and Human Capital}

Previous studies demonstrate that service in the military may lead to increased skills and the ability to perform in the civilian sector (Cooney, Segal, Segal, and Falk 2003; Browning, Lopreato, and Poston 1973). The set of constructive skills and the egalitarian atmosphere provided by the military is often referred to as a "bridging environment". Service in the military removes people from familiar environments and offers a diverse group of coworkers, providing access to increased levels of social capital, while also educating service members with skills and knowledge that may be relevant to the civilian marketplace (Cooney et al. 2003). This environment may be 
especially beneficial for women, racial minorities, and those with lower levels of education who may have lacked access to these forms of capital prior to their military service (Cooney et al. 2003). If veterans are able to capitalize on these bridging environment factors they should have economic benefits in the civilian sector (Beusse 1974; Teachman and Tedrow 2007). If the military does not impart beneficial skills or the veteran is unable to utilize them in the civilian economy, the veteran will likely achieve lower levels of income following release from service.

The military acts as an egalitarian workplace which may allow minority populations to overcome previous disadvantages brought on by unequal access to resources (Sampson and Laub 1996; Teachman and Tedrow 2007) or discrimination and poverty (Daula, Smith, Nord 1990; Little and Fredland, 1979; Lopreato and Poston, 1977; Martindale and Poston, 1979; Seeborg, 1994; Teachman and Tedrow 2007). Ultimately, this suggests that the military provides an environment in which those disadvantaged in society can, at the very least, act in a space that is relatively free of discrimination or fraught with difficulties-- a level playing field that may allow disadvantaged people to obtain greater resources and economic benefits than they would otherwise achieve.

Researchers have found that those who are disadvantaged in the civilian sector tend to experience increased levels of civilian economic performance following military service. For instance, minority males tend to receive more benefits from their service than white males (Cooney et al. 2003; Kogut, Short, Wall 2010; Teachman and Tedrow 
2007; Teachman 2007). Those men with lower levels of educational attainment tend to receive greater benefits compared to other veterans (Cooney et al. 2003; Kogut, Short and Wall 2010; Teachman and Tedrow 2007). These findings also hold when controlling for race and age (Detray 1982). Other research shows that those with a history of delinquency also benefit from military service (Maclean 2008; Teachman 2007; Teachman and Tedrow 2007). In a society such as the United States, in which institutional racism and stereotypes abound, military service may diminish the negative effects of these problems.

\section{Social capital}

According to Bourdieu (1986) social capital is a collection of real or potential resources which can be accessed by membership in the dominant group. Access to this group allows members to utilize resources, owned not by the individual, but by others in the group. Whether it is knowledge concerning the local labor market, the location of good paying jobs, or what employers are hiring, the social and economic ties available to a person directly relate to their economic wellbeing (Teachman and Tedrow 2007). According to Bourdieu (1986) social capital is convertible into economic capital which, “...is immediately and directly convertible into money and may be institutionalized in the form of property rights..."(47). This means that social relationships can be utilized to create opportunities to positively impact economic performance. 
Teachman and Tedrow (2007) find that veterans, due to their military service and subsequent removal from the civilian labor force, experience decreased social capital in the form of social and economic ties. The social capital perspective suggests that veteran earnings should increase as they spend more time in the civilian labor force and presumably rebuild these ties (Teachman and Tedrow 2007). Conversely it is possible that veterans who spend time in the military may build significant ties which allow for economic benefits following their service. Longer service in the military may be associated with stronger or more numerous social ties. These social ties formed in the military may lead to economic opportunities that allow for continued work with the military or governmental establishments as a civilian employee.

\section{Life Course Perspective}

Alwin (2012) attempts a comprehensive definition of the literature surrounding the life course theory. The life course theory assumes the existence of cohorts of individuals who experience similar changes as they progress through life stages, filled with unintentional and intended experiences which limit or broaden choices, which singularly and together compound one another to affect the life trajectories and overall outcomes of the people (Alwin 2012). The life course perspective, building upon the two previous theoretical perspectives, focuses on the effects of major life events and how they alter the choices available to a person (Teachman and Tedrow 2007; Teachman 2007). This perspective suggests that two possible outcomes may result from 
military service: 1) removal from the civilian sector decreases veteran civilian participation and therefore their future wages; 2 ) conversely the application of skills learned while serving in the military may neutralize any negative wage effect expected (Teachman and Tedrow 2007). Teachman and Tedrow (2007) summarize the effects of military service clearly, explaining that, “...the extent to which military service reduces labor market experience, it should reduce income" (1450).

\section{Veteran Status as a Potential Verification of Worker Quality}

Military service, and the honorable discharge, act as what Teachman and Tedrow (2007) call, "...an easily observed proxy, a screening device, for an assumed store of social and human capital" (1453). In this way, military service acts as proof of a set of skills, or human capital, that employers can use in lieu of actual civilian employment to judge job applicants. Part of the assumption by employers is that a certain type of person is able to serve, a person who is believed to be physically and mentally healthy (Teachman and Tedrow 2007). The overall effect of this screening behavior seems to be beneficial only to those who are generally disadvantaged by some other minority status (Teachman and Tedrow 2007).

\section{Variations in Veteran Status}

Overall it appears that due to discriminatory beliefs and practices, disadvantaged groups like racial minorities and women have lower levels of economic performance as compared to White males. Furthermore, racial and gender discrimination negatively 
affect human and social capital acquisition which influences differences in economic performance between groups. While employment rates appear to be changing, differences still exist. Perhaps veteran status can make up for diminished levels of economic participation, human capital, and social capital acquisition. Because these disadvantaged groups face difficulties when obtaining various forms of capital, veteran status may work to decrease these disadvantages and therefore increase access to economic opportunities. 


\section{Impact of Veteran Status}

Veteran status may provide some form of benefits to civilian economic performance. However there are many factors that exist, such as race, gender, education, and more that may interact and alter the impact of veteran status. Past research will show, while veteran status is beneficial, it generally benefits a small portion of those who serve in the military.

\section{Education and Military Service}

Military service has often been associated with positive outcomes over the life course. For example, Barley (1998) argues the military has consistently made service in the military appear beneficial to later civilian economic performance. Teachman and Tedrow (2007) state that historically, the military has acted as not only the largest employer of young men but also as, "...the largest vocational school in the nation" (1447). If the military is indeed the largest employer and vocational school, research should be done to verify the validity of the claims being made. The following is a survey of relevant research concerning the relationship between military service and educational attainment. Research does not appear to provide consistent results; researchers find positive and negative effects of military service on economic performance.

Military training is believed to add human capital for veterans by assisting in the development of skills that may be useful in the civilian sector (Cooney et al. 2003; 
Kleykamp 2009) these skills may come in the form of job training in specific fields and the strengthening of traits like discipline and leadership. Outside of training related directly to the creation of tangible skills, military service may impart characteristics that assist in the marketability of a veteran such as dependability, communication skills, and teamwork (Kleykamp 2009). Additionally, discipline and leadership skills can be enhanced (Hope, Oh, and Mackin 2011; Teachman and Tedrow 2007). Evidence of these skills for civilian sector employers comes in the credentialed form of an honorable discharge from the military (Kleykamp, 2009; Teachman and Tedrow 2007). Lastly, those who serve on active duty, as of 2001, are eligible for educational benefits after they separate from military service (Cooney et al. 2003) which may assist in increasing the wages the veteran may earn (Hope, Oh, and Mackin 2011). These recent educational benefits have provided increased funding which may increase the attractiveness of obtaining and make possible further schooling for veterans.

Kleykamp (2010) reports that a reduction in military service time is related to higher rates of employment and school attendance in the civilian sector. Utilizing the Current Population Survey for the years from 1980 to 2000, Kleykamp (2010) analyzed employment and education enrollment rates following military growth in the 1980 s and subsequent downsizing in the 1990s. Analyses are performed on groups based on age, race, and educational level. Kleykamp (2010) finds that in general the impact of a military drawdown on educational and employment rates is moderate; employment 
rates had a slight increase regardless of race while college enrollment increased significantly for Black men. Military service may be positively correlated with increased educational attainment for those who serve, specifically minorities. Kleykamp (2010) suggests however that military service may have limited the educational progression of black men due to the negative association between military service and later educational attainment.

While skill attainment is important for economic wellbeing, obtaining legitimate credentials in the form of formal education drastically impacts a person's wellbeing. Teachman (2007), utilizing the NLSY from 1979 to 2000 performed an analysis of men who were between the ages 17 to 21 in 1979 with an interest in the highest degree completed by respondents. In general, military service appears to be negatively associated with later educational attainment (Teachman 2007). However those who join at older ages are more likely to seek out further education following service; this increased educational attainment is likely to make up for a lack of civilian economic experience (Teachman 2007). Teachman (2007) states that length of service in the military is negatively related to educational attainment, however this might lead to a stronger desire to seek out more credentials due to decreased civilian labor force participation.

Since the 1960s, men who serve in the military have had lower levels of educational attainment than those who did not serve (Cohen, Segal, and Temme 1986; 
Cohen, Warner, and Segal 1995; MacLean 2005); this may lead to lower economic performance for veterans as compared to non-veterans. While veterans tend to come from families of lower status and income, veterans of all SES levels were less likely than non-veterans to go on to college (MacLean 2005). Military service appears to be a disruption for some veterans (MacLean 2005); both those who were drafted and those who planned to continue on to college following service had decreased odds of attending (MacLean 2005). However, MacLean (2005) states that veterans were more likely to perform the normative actions of getting married and finding work as compared to non-veterans. Military service may dampen later educational attainment; but service may act as a replacement credential for those with only high school educations thus leading to their increased levels of economic performance.

While veterans in general have lower educational attainment than non-veterans some, such as officers, must have at least a college degree in order to serve. It may be the case that any veteran wage benefit that exists may be due to the differences that exist between officers and enlisted service members. After controlling for race, rank, and era of service Hirsch and Mehay (2003) report a 3 percent wage advantage for veterans; among enlisted personnel this wage advantage becomes zero. Hirsch and Mehay (2003) further report that veteran reserve officers have a wage advantage against non-veteran reserve officers. Perhaps those who serve on active duty and as officers have greater access to human and social capital; furthermore their positions in 
the military may be viewed as more positive than others thus added higher levels of status.

Social class influences whether a service member will be enlisted or a commissioned officer which in turn determines the likely benefits they will receive from their service. Compared to enlisted soldiers, officers generally come from families of higher socioeconomic standings (MacLean 2008). MacLean (2008) finds that during the peacetime draft era men with a high socioeconomic background were just as likely to serve as those from a low socioeconomic background; however men with a high SES were more likely to be officers. Veterans who served as officers reported increased economic outcomes as compared to non-veterans, whereas enlisted veterans had lower outcomes (MacLean 2008). MacLean (2008) suggests that these differences may be due to statuses that existed prior to service; enlisted soldiers began with less than officers did, thus decreasing enlisted veterans' outcomes.

The impact of education is substantial; in the military, education may be influential in determining who experiences combat. MacLean and Parsons (2010) report findings that when filling combat occupations in the all-volunteer era (AVE), people with fewer skills or education are more likely to be selected. MacLean and Parsons (2010) state that in all eras of military service, including draft and AVE, the military assigns combat occupations based on military test scores, therefore those with higher education or skills were offered high-skill non-combat occupations. Race, family 
structure, and parental education affect the assignment of combat occupations (MacLean and Parsons 2010). Men with lower educational attainment were more likely to serve in combat positions (MacLean and Parsons 2010); men from families with high educational resources, specifically if at least one parent had graduated from college, were less likely to see combat (MacLean 2011). Those who performed better in school were more likely to go on to college rather than join the military, thus making them less likely to serve in combat positions (MacLean 2011; MacLean and Parsons 2010) those with lower levels of education were also less likely to join the military than those with high school educations (MacLean 2011). While family income was not found to influence military outcomes, parental educational level, namely achieving less than high school or graduating college, decreased military service likelihood (MacLean 2011). Assignment to a combat occupation is important since it is likely that these positions are more likely to be exposed to conditions that contribute to later negative health consequences and lower economic performance.

Because of the differing levels of education required to serve as an officer, there may be differing military service experiences and lessons learned by service members. MacLean (2008) reports that a majority of Cold War era veteran participants describe the military as playing a "transitional role" which was neither negative nor positive; veteran officers described learning skills such as leadership while enlisted veterans learned discipline (MacLean 2008). MacLean (2008) states that some veteran 
experiences were consistent with the military acting as a "disruption", citing negative situations like crime and violence. Overall MacLean (2008) states that the general neutral descriptions of military experiences contradicts past negative research findings which show military service as interrupting life progression. MacLean (2008) suggests that the wage premium often obtained by veterans of officer rank may be due to the different skills and experiences received while serving.

It is clear due to previous research that the military provides some level of capital or skills (Cooney et al. 2003; Hope et al. 2011; Kleykamp 2009; Teachman and Tedrow 2007) which may be beneficial to veterans in the civilian economy. However, those who serve are not only less likely to enter with higher degrees (Cohen et al. 1986; Cohen et al. 1995; MacLean 2005) but service in the military has been negatively associated with later levels of educational attainment (Teachman 2007). Furthermore it appears that officers, those who must enter with higher levels of education, may be primarily responsible for the apparent positive economic outcomes following military service. Whether officers benefit economically more so than enlisted service members (Mehay 2002) or they experience combat and the negative consequences associated with it less (MacLean and Parsons 2010) education may shape later economic performance. At the very least, education appears to shape the specific skills that are developed while in the military (MacLean 2008) which may ultimately shape the future civilian economic experiences of veterans. 


\section{Race}

Due to prejudiced and racist practices, racial minorities tend to be disadvantaged in the civilian labor market. Military service may advantage these same racial minorities so as to provide increased economic performance. Research shows that Black and Hispanic veterans tend to receive more income as compared to their non-serving counterparts. While era of service may affect later outcomes, it appears that racial minorities experience economic advantages compared to those who did not serve.

Browning, Loreato, and Poston (1973) report that generally Black and Mexican American veterans receive income advantages as compared to their non-veteran counterparts. Browning et al. (1973) find the Mexican American veteran income advantage is greater than that experienced by Black veterans, after controlling for increased wages often received by Mexican Americans. Despite this income advantage, in occupations in which peoples' experience and time at the company determine rising wages, Blacks and Mexican Americans do not receive an income advantage from veteran status (Browning et al. 1973). Further research shows that after controlling for race, Black veterans receive positive economic returns (Hirsch and Mehay 2003).

Teachman and Tedrow (2007) find that White male veterans that completed high school generally experienced long term negative impact on income; those veterans, both Black and White, with less than high school and Black veterans with a high school education, at the very least, averaged similar levels of income as compared to non- 
veterans with similar education (Teachman and Tedrow 2007). Interestingly, Black males and those who have lower levels of education achieve higher levels of income as compared to their non-serving counterparts (Teachman and Tedrow 2004, 2007). Similarly Black veterans who were enlisted have higher educational attainment and positive economic performance as compared to similar non-veterans (Hisnanick 2003). There does not appear to be a relationship between the length of military training, the schooling received to prepare a service member to perform their military occupation, and subsequent civilian income (Teachman and Tedrow 2007). Overall, military service appears to disadvantage a majority of white males (Teachman and Tedrow 2007) service in the military may provide an egalitarian environment in which those normally disadvantaged can succeed and later apply that success in the civilian labor force.

Teachman and Tedrow (2004) state that WWII veteran economic performance is not due to family differences, like parental education, occupation, and marital status. Instead WWII veteran economic performance may differ from non-veterans due to increased skill investment in the military and in the civilian sector in the form of college (Teachman and Tedrow 2004). After controlling for skill investment, Blacks and less educated veterans earn higher wages as compared to similar non-veterans; this finding shows that the veteran premium is not due to education and skill attainment alone (Teachman and Tedrow 2004). Teachman and Tedrow (2004) state that the poor 
situation of Black veterans may be due to the case that Black veterans are less able to convert their education into high status occupations as compared to White veterans.

Kleykamp (2009) performed a correspondence test in which similar resumes were sent to employers in order to test the effects of veteran status on hiring practices. Kleykamp (2009) shows that veterans with job experience applicable to their civilian occupation were treated similarly to non-veterans, except for Black veterans. However Black veterans with administrative experience were treated favorably (Kleykamp 2009). Furthermore, employers' disadvantaged those veterans without transferable skills. While Black veterans without transferable skills faced large disadvantages with regards to hiring from employers, Hispanic veterans with the same skill level did not suffer negatively (Kleykamp 2009). Kleykamp (2009) states that employers evaluate applicants based on their level of human capital and only then is military service taken into account. If a veteran obtained applicable capital from their military service, it is likely that their military service will provide them with an advantage in the civilian labor force, at the very least they may be viewed as equal to those who did not serve in the military.

While race is a vital component in determining the economic performance of veterans, the era in which they served also plays a strong role. Martindale and Poston (1979) find a wage advantage was earned for Black WWII, Korea, and Vietnam veterans after controlling for education, weeks worked, and marital status. Hispanic and White veterans of WWII and Korea were found to have similar wage increases (Martindale and 
Poston 1979). However Hispanic and White veterans from the Vietnam era had a negative impact on earnings where Black veterans did not (Martindale and Poston 1979).

Next Martindale and Poston (1979) analyzed how well veterans were able to convert educational attainment, weeks worked in the civilian labor force, and marital status into earnings. Black veterans of all eras are better able to convert education, weeks worked, and marriage into increased income as compared to similar nonveterans (Martindale and Poston 1979). Hispanic veterans of the WWII and to a lesser extent Korea earned increased wages for educational attainment and marital status while Vietnam era veterans have increased earnings from education and weeks worked as compared to nonveterans (Martindale and Poston 1979). Lastly, White veterans appear to have a greater ability to convert education to earnings in all three eras and White Korean and Vietnam War veterans have a greater ability to convert weeks worked into increased income (Martindale and Poston 1979). White non-veterans appear to have a better ability of utilizing marital status to an economic advantage, especially in the Vietnam era as compared to veterans (Martindale and Poston 1979). Martindale and Poston (1979) suggest that benefits obtained by WWII veterans could be due to service in a popular war.

Greenburg and Rosenheck (2007) present further findings concerning race, era of service, and economic success. They analyzed data from 1989 to 2003 and found that 
veterans of WWII and the Korean War and Black veterans of the interwar period had low rates of unemployment during that period (Greenburg and Rosenheck 2007). White Vietnam veterans had an increasing rate of unemployment from 1989 to 2003 and postVietnam White veterans had higher rates of unemployment as compared to nonveterans. Black and Hispanic Vietnam veterans did not differ from similar non-veterans in all three major eras of service (Greenburg and Rosenheck 2007). These differences between White and minority veterans may be due to differing backgrounds; White Vietnam veterans were more likely to come from working class families with less education than minority Vietnam veterans (Greenburg and Rosenheck 2007). This finding may suggest that White veterans, specifically those from Vietnam, may have lower levels of economic performance following service than their non-veteran counterparts. Both studies by Martindale and Poston (1979) and Greenburg and Rosenheck (2007) show that veteran economic success is closely tied to not only race but also the era in which they served.

Those who are married often receive advantages in the form of social interaction and increased incomes as compared to those who are not married. Teachman and Tedrow (2008) find that divorce rates are decreased for Black men in the Army; they suggest that these results are not due to selectivity because of the high proportion of Black service members, as compared to civilian labor force, and the increased concentration of Black men in senior enlisted ranks. Teachman and Tedrow (2008) 
further suggest that these findings may indicate that increased levels of equality may bring about increased marital success for groups that face discrimination. Prior to 2001, divorce rates for the Army were lower than in the civilian sector, by 2004, after increased military actions, the divorce rate for the Army increased by 58\% (Teachman and Tedrow 2008).

Due to race, veterans experience differential economic outcomes. Some research has found that Black and Hispanic veterans receive income advantages as compared to their non-veteran counterparts (Browning et al. 1973). Other research has found that both low educated White and all Black veterans manage similar levels of income as compared to non-veterans (Teachman and Tedrow 2007). It may be the case that Black veterans are less able to convert formal education into economic benefits as compared to White veterans (Teachman and Tedrow 2004). Based on the era one serves, race may impact economic performance. Black veterans of all eras were found to experience a wage advantage as compared to Black non-veterans while Hispanic and White veterans experienced benefits in all eras except for Vietnam (Martindale and Poston 1979). Similar research found that White veterans of the Vietnam era experienced higher rates of unemployment relative to non-veterans, Black and Hispanic veterans did not differ from their non-veteran counterparts (Greenburg and Rosenheck 2007). Overall it appears that racial minorities tend to benefit from military service while White veterans have mixed outcomes. 


\section{Gender}

Research has shown mixed outcomes from military service based on gender. For women, military service may socialize them into the generally male dominated work culture and provide familiarization with the bureaucratic environment typical of the United States which may serve to increase female performance in the civilian sector (Cooney et al. 2003). Female veterans of active and reserve duty may also be less likely to marry (Cooney et al. 2003; Mehay and Hirsch 1996) and more likely to limit the number of children they have (Cooney et al. 2003). The former may act to limit economic earnings potentials but combined with the latter, female veterans may experience decreased gender role strains. However, Mehay and Hirsch (1996) do report that female veterans are more likely to have younger children. If female veterans are more likely to limit the number of children they have as compared to female nonveterans, they are likely to experience less gender role strain as compared to their nonserving counterparts. Those women who marry or care for multiple children may encounter increased levels of stress in the home brought on by gender roles which may be further complicated by outside employment. Women with fewer or no children are likely to have higher levels of income than those with more children.

As shown previously, education has a drastic impact on veteran performance. Education alone is not all important. Gender for both veterans and non-veterans shapes the economic experience. Mehay and Hirsch (1996) with the use of three separate 
datasets find that female veterans experience higher levels of earnings endowments than non-veterans. These advantages for female veterans are greater among non-white as compared to white respondents and those with college degrees as compared to those without reservists (Mehay and Hirsch 1996). This second result shows that an increase in human capital, in the form of formal educational and experience, may be directly related to increased economic performance of female veterans as compared to female non-veterans.

Kogut, Short, and Wall (2010) report that veterans receive an earnings advantage as compared to non-veterans and further that female veterans earn more than male veterans. Contrary to Mehay and Hirsch (1996), Kogut et al. (2010) report that the income advantage for veterans is strongest for those who have lower educational levels. Kogut et al. (2010) estimate that men with lower educational levels who join the military earn on average $10 \%$ higher wages; this advantage is stronger for women of low education with a $12 \%$ income increase.

Despite these positive findings, conflicting evidence concerning the economic performance of female veterans exists. Cooney, Segal, Segal, and Falk (2003) report that no group of female veterans, regardless of race and military status, as compared to non-serving counterparts had an economic advantage (Cooney et al. 2003) at the very best, the research found that only Black female veterans managed to achieve similar levels of family income as compared to non-serving counterparts. 
Research suggests that non-white female veterans are more likely to work in the public sector (Mehay and Hirsch 1996) this finding may account for increased economic performance of non-white female veterans. Overall it appears to be the case that white female veterans are disadvantaged based on educational attainment than their nonserving counterparts (Cooney et al. 2003) and that white female veteran reservists were found to have wage disadvantages as compared to their civilian counterparts (Mehay and Hirsch 1996).

Murdoch, Hodges, Hunt, Cowper, Kressin, and O'Brien (2003) report that female combat veterans are $19 \%$ less likely than males to receive compensation from the VA for PTSD claims. It must be noted that these results come in 2003 which was early during the Gulf War II era, claims management may be different for those respondents who participated in this survey from 2010. If these results hold merit they suggest that women who experience combat are less likely to receive beneficial recognition from the VA which can positively influence income in a multitude of ways. Murdoch et al. (2003) state that veterans who are granted service connected disabilities receive access to priority care at the VA which is also correlated to healthcare utilization rates. A lack of compensation or recognition by the VA may lead to decreased economic performance for female combat veterans if they experience any negative side effects, physical or mental, from their service. 
Research regarding the economic impact of veteran status and gender is indeterminate. Some research shows that female veterans are more educated and have higher levels of human capital than non-serving counterparts which leads to increased economic performance (Mehay and Hirsch 1996). Some research shows that while female and male veterans earn more than their non-veteran counterparts, the advantage is strongest for those with lower levels of education (Kogut et al. 2010). And yet still, other research finds that no group of female veterans had an economic advantage, and only Black female veterans achieved similar levels of family income as compared to non-veteran counterparts (Cooney et al. 2003). Ultimately, results regarding the effect of gender and veteran status on economic performance are conflicting at best.

\section{Era of Service}

The different statuses and experiences that veterans have and the type of service, be it drafted or non-drafted, may influence later civilian economic performance. After controlling for background characteristics and labor experience, the negative effect of Vietnam veteran status on income is generally due to being drafted (MacLean 2008; Teachman 2004). Despite receiving a negative penalty on income, drafted veterans have a steeper income trajectory than non-veterans which quickly diminishes the differences between them (Teachman 2004). Teachman (2004) states that nondrafted Vietnam era veterans experienced an income premium as compared to non- 
veterans. Teachman (2004) suggests that the negative effects of being drafted may be due to disruption of their lives and that this disadvantage fades as the time since separating from the military increases.

An important factor in determining veteran economic outcomes is accounting for the era in which they serve (Teachman and Tedrow 2007). It may be the case that the type of war and the number of those who served may determine later benefits veterans experience; wars characterized by involuntarily service or low levels of popularity may be related with negative feelings toward those who served. Those veterans who served during the Vietnam era have consistently poorer economic performance than their non-veteran counterparts (Carl, Short, Wall 2010; Hirsch and Mehay 2003; Maclean 2008; Teachman and Tedrow 2007). From Vietnam until 1998 veterans were experiencing from $11-19 \%$ reduction in earnings due to their military service as compared to non-veterans (Barley 1998). Furthermore those who served during the Vietnam era received less financial assistance for education in the form of the GI Bill (Teachman 2007); lower educational attainment rates are positively correlated with lower economic performance. Barley (1998) explains that employers are likely to give preference to veterans if the cohort they served with is large, such as in WWII, likely assuming that those that did not serve were rejected and are somehow inferior to veterans. 
Conflicting results exist concerning the economic performance of World War II veterans. Some research has found Service during World War II to be positively correlated with later civilian income (Teachman and Tedrow 2007) veterans from World War II who utilized their training from military service in the civilian sector appeared to earn a $12 \%$ earnings increase as compared to non-veterans (Barley 1998). Conversely, Angrist and Krueger (1994) state that, according to analyses based on the 1960, '70, and '80 censuses, WWII veterans did not earn a wage premium as compared to nonveterans controlling for age; instead they suggest that those who served in WWII would have earned more if they had not served in the military. Even among the same cohort, research on economic performance differs. As pointed out by Barley (1998), veterans who managed to utilize skills gained from their service managed to earn greater wages; perhaps higher levels of capital, human capital, assisted in this wage increase.

These conflicting economic outcomes due to era and type of service are vital to understanding the economic performance of veterans. Recent research shows that, as compared to Cold War era veterans, recent veterans have tended to earn more than their civilian counterparts (Maclean 2008). It could be the case that capital obtained from service eras that are not valued, is perhaps devalued in the civilian labor market. Further research is necessary to understand how those who have served in the Gulf War Il era will perform in the civilian economy. 


\section{Wealth Accumulation and Active Duty}

While some veterans may earn a wage benefit from their service, wages do not equate wealth. As noted in the discussion on race, wealth is not as equally available as income may be to all people. Fitzgerald (2006) presents findings that show, generally, that veterans of active duty military service had an increased likelihood of low wealth accumulation. For veterans who serve for three and ten years, there is a negative impact on wealth accumulation of approximately $14 \%$ and $45 \%$ respectively as compared to non-veterans (Fitzgerald 2006). Fitzgerald (2006) continues by stating that this wealth differential between veterans and non-veterans may be due to a decreased likelihood of homeownership, which is seen as a primary wealth building method. Due to the decreased development of wealth, veterans may experience some negative economic consequences.

\section{Disability}

Another difference that may exist between the officer and enlisted veteran is the reported health following service. MacLean and Edwards (2009) report that after controlling for socioeconomic factors, officers in the military report better health as compared to enlisted men; this appears to be a result of increased length of service which coincides with a decreased experience of the negative effects of being Black in the United States. Furthermore, MacLean and Edwards (2009) state that military service is associated with decreased racial disparity when considering job satisfaction 
and marital status. While officers are more likely to report combat exposure, it may be the case that officers tend to serve in less dangerous positions than enlisted members (MacLean and Edwards 2009), this may account for some of the health differences. Among veterans, those who served as officers also report increased levels of health, as compared to those who served as enlisted; this may be related to the possibility that officers are more likely to receive disability from the VA (MacLean and Edwards 2009). MacLean (2010) reports that for veterans, combat exposure is positively related to increased disability and unemployment rates; these increased rates disadvantaged combat veterans' short and long term economic performance. Combat veterans are more likely than non-combat veterans to suffer from work-related disabilities (MacLean 2010) combat veterans are more likely to suffer from PTSD and other mental disorders (Hoge, Castro, Messer, McGurk, Cotting, and Koffman 2004). These findings may lead to decreased economic outcomes due to difficulties performing in the civilian labor force.

Disabilities have a drastic impact on the economic performance of all people. Heflin, Wilmoth, and London (2011) report that households that include someone with a disability generally experience more material hardship (food insufficiency, medical, housing, and bill-paying) as compared to similar non-disabled families; disabled veteran families have higher rates of hardship as compared to non-disabled veteran families (Heflin et al. 2011). Heflin et al. (2011) state that their research is limited due to their lack of differentiation amongst disabilities and their differing impacts on hardships 
coupled with the unmeasured effects of participation in disability and veteran programs that may increase wellbeing or decrease hardships.

Combined with veteran status, disabilities may compound or alleviate problems experienced. According to London, Heflin, and Wilmoth (2010) households with a veteran are less likely to be in poverty, while those with a disabled veteran have a decreased advantage (London et al. 2010). It may be the case that veteran households in which someone is disabled are more likely to have a non-disabled primary earner, whereas non-veteran disabled households may rely on the disabled primary earner (London et al. 2010). London et al. (2010) state that the military may advantage veterans due to education and experience that creates capital that may be useful in the civilian labor force. Coupled with training comes an increased access to benefits and services for veterans following their release from active duty; these services are provided to veterans who are often viewed as deserving due to their sacrifices and service (London et al. 2010). London et al. (2010) report that it may be that financial support which comes from the Veteran's Administration may help to decrease the risk of poverty for disabled veterans.

Veterans of active duty service do not report better health as compared to reserve-duty veterans and non-veterans who passed the same physical exam (Teachman 2011). Teachman (2011) finds that active duty veterans report lower levels of health as compared to reservists and civilians; reservists and civilians who passed the physical 
exam report higher levels of health as compared to all other civilians (Teachman 2011). If it is the case that active duty veterans enter the civilian workforce with lower levels of health, they may be disadvantaged economically; conversely it is possible that, due to subsidies from the VA, active duty veterans with lower health are neutrally or positively affected economically.

Combat veterans may be more likely than non-combat veterans and nonveterans, due to their experiences, to develop symptoms associated with Post Traumatic Stress Disorder (PTSD) (Wilcox 2010;176). PTSD developed from combat experiences has a strong negative effect on social relationships (King, Taft, King, Hammond, and Stone 2006; Renaud 2008), like those in marriages and families, and on performance at work (Renaud 2008). Ginzburg, Ein-Dor, and Solomon (2010) state that PTSD is strongly correlated with symptoms of anxiety and depression which may further negatively impair veteran functioning in the civilian sector. Decreased social support may lead to a decrease in economic performance, due to lower levels of social capital to draw from; furthermore veterans with PTSD may have difficulty working in environments that require social interaction. Those who are diagnosed with mental disorders struggle with their occupational functionality (Erebes, Kaler, Schult, Polusny, and Arbisi 2011). However those with mental disorders were not less likely to be employed or in school; it is suggested that veterans with mental disorders are likely to maintain employment because of social norms and employment assistance programs 
which both support veterans (Erebes et al. 2011). Erebes et al. (2011) suggest that in general, with the increase in military actions of the current day, the presence of mental disorders in service members may increase and negatively impact the occupational functioning of veterans. This negative functioning may not immediately manifest in the form of lower wages, but instead in fewer worked hours, poorer reviews, and fewer promotion opportunities (Erebes et al. 2011) which ultimately decrease the economic performance of these veterans.

Households that contain a person with a disability are more likely to experience material hardship (Heflin et al. 2011). Disabled veteran families were found to have higher rates of hardship as compared to non-disabled veteran households (Heflin et al. 2011). It has been found that, due to rank and thus educational levels, officers are less likely to report low levels of health as compared to enlisted soldiers (MacLean and Edwards 2009). What this may mean is that enlisted service members may be more likely to have poorer health which then follows them as they become a veteran in the civilian sector. Furthermore, those who experience combat are more likely to incur a disability from their service (Hoge et al. 2004; MacLean 2010) or more likely to report low levels of health. Veterans, and more specifically combat veterans, may be more likely to experience a negative impact on their civilian economic performance due to service connected experiences. 


\section{Research Questions and Hypotheses}

The following research questions and hypotheses are motivated by the theoretical lenses and previous literature provided in former sections of this thesis.

- How does veteran status affect household income?

- Informed by previous research regarding the positive skill building characteristics of the military (Browning et al. 1973; Beusse 1974; Cooney et al. 2003; Teachman and Tedrow 2007) it is hypothesized that veterans will have higher household incomes than non-veterans.

- How does the effect of veteran status on household income differ by gender?

- Among veterans, the gender income gap will be smaller as compared to the gender gap among non-veterans; female veterans will earn more than their non-veteran counterparts. This is motivated by previous research regarding the relationship between gender and veteran status (Cooney et al. 2003; Kogut et al. 2010; Mehay and Hirsch 1996).

- How does the effect of veteran status on household income differ by race?

- Veterans of minority race will experience a wage premium as compared to their non-veteran counterparts; non-minority veterans will experience similar levels of household income as compared to 
similar non-veterans as noted by previous research regarding the effect of military service on economic performance (Daula et al. 1990; Little and Fredland 1979; Kogut et al. 2010; Lopreato and Poston 1997; Martindale and Poston 1979; Sampson and Laub 1996; Seeborg 1994; Teachman and Tedrow 2007).

- How does the effect of veteran status on household income differ by educational attainment?

○ Motivated by previous literature (Cooney et al. 2003; Hope et al. 2011; Kleykamp 2009; Teachman and Tedrow 2007) veterans with lower levels of education will experience a wage premium as compared to their non-veteran counterparts.

- What effect does combat status have on household income among veterans?

- Veterans who experience combat will experience a wage disadvantage as compared to non-combat veterans due to an increased likelihood of disability (Erebes et al. 2011; Heflin et al. 2011; London et al. 2010; MacLean 2010; Renaud 2008; Wilcox 2010). 


\section{Methods}

\section{Data}

The dataset used for this analysis is the Current Population Survey July 2010 with Veterans Supplement. This survey is the official source of governmental statistics concerning employment in the United States (Userguide 2010). The total sample is drawn from all non-institutionalized households living in the United States and consists of 153,705 records from 56,000 households (Userguide 2010). The Current Population Survey is designed to obtain a nationally representative sample of respondents. According to the CPS, this sampling method is regularly updated to compensate for changes within the population of the United States.

Prior to performing this study the appropriate weight and filters were applied to the data. For this study two filters were applied to the overall sample. Specifically, these analyses will only involve those respondents who are between the ages of 18 and 64 , to ensure that results represent the population of the United States that is of working age. Furthermore, those respondents with a household member who is currently serving in the active duty military have been excluded. It is likely that these families differ significantly from the civilian population due to lower rates of pay and the possibility for receiving payments such as the Basic Allowance for Housing and the Basic Allowance for Subsistence which may alter income levels. These payments, and the military environment may impact the earnings of those who belong to a military family 
in such a way as to act as outliers which may skew results. Lastly, the last filter is for those respondents who are coded as system missing for any variables involved in this study. Overall the filters utilized decrease the CPS sample from 153,705 cases to 83,000 cases or $54 \%$ of the original sample.

\section{Measures}

The primary dependent variable of this research is household income. This variable is a measure of the "...combined income of all family members during the last 12 months. [This variable] includes money from jobs, net income from business, farm or rent, pensions, dividends, interest, social security payments and any other money income received by family members who are 15 years of age or older" (User guide 2010: 8). This variable is an ordinal variable with a scale that ranges from less than $\$ 5000$ to $\$ 150,000$ or more; the structure of this variable can be observed in Table 1.

The secondary dependent variable of this research is occupation type. This variable is a measure of the major occupational categories as identified in the Current Population Survey (User guide 2010). This variable is nominal and has the following categories: management, professional, and related occupations, service occupations, sales and office occupations, farming, fishing, and forestry occupations, construction and maintenance occupations, production, transportation, and material moving occupations, and armed forces occupations. Those in the armed forces occupations 
were removed from analyses involving this variable due to the minimal frequencies received for this variable.

Household income accounts for the total amount of earnings within the family and therefore can provide an accurate understanding of the likely situation and environment that a respondent inhabits. Household income also has the highest response rate of all income variables. For the variables of weekly and hourly personal earnings, the response rate falls below $20 \%$, a fact that would drastically impact the ability to generalize any results obtained from their usage.

There are five primary independent variables included in this research. One primary independent variable is veteran status which is measured by the question, "have you ever served on active duty" (Codebook 2010: 33). Previous active duty service is generally the defining factor for veteran service. While the experiences of those in the reserves is important, this research primarily seeks to understand the experience of active duty personnel. This variable includes all veterans of active duty service; it does not differentiate by rank or between those who have experienced combat and those who have not.

For the second primary analyses which will illuminate differences among veterans, the combat veteran variable is used. This variable was constructed from the question, "Did (you/name) EVER serve in a combat or war zone? Persons serving in a combat or war zone often receive combat zone tax exclusion, Imminent Danger Pay, or 
Hostile Fire Pay." (Codebook 2010: 250). This variable measures whether someone ever served in a combat zone or area which may be associated with experiencing traumatic events or difficult circumstances. 749 Veterans were "Not In Universe" for this variable and so were excluded from the combat veteran analyses.

\section{Table 1: Household Income Categories}

(weighted \%)

\begin{tabular}{|c|c|c|c|}
\hline & Household Income & Frequency & Valid Percent \\
\hline 1 & Less than $\$ 5,000$ & 2174 & 2.65 \\
\hline 2 & $\$ 5,000-\$ 7,499$ & 1401 & 1.67 \\
\hline 3 & $\$ 7,500-\$ 9,999$ & 1650 & 2.01 \\
\hline 4 & $\$ 10,000-\$ 12,499$ & 2248 & 2.81 \\
\hline 5 & $\$ 12,500-\$ 14,999$ & 1978 & 2.50 \\
\hline 6 & $\$ 15,000-\$ 19,999$ & 3335 & 4.20 \\
\hline 7 & $\$ 20,000-\$ 24,999$ & 4417 & 5.54 \\
\hline 8 & $\$ 25,000-\$ 29,999$ & 4557 & 5.71 \\
\hline 9 & $\$ 30,000-\$ 34,999$ & 4577 & 5.71 \\
\hline 10 & $\$ 35,000-\$ 39,999$ & 4477 & 5.59 \\
\hline 11 & $\$ 40,000-\$ 49,999$ & 7348 & 8.84 \\
\hline 12 & $\$ 50,000-\$ 59,999$ & 7695 & 9.19 \\
\hline 13 & $\$ 60,000-\$ 74,999$ & 9347 & 10.89 \\
\hline 14 & $\$ 75,000-\$ 99,999$ & 10762 & 12.65 \\
\hline 15 & $\$ 100,000$ - \$149,999 & 10234 & 11.94 \\
\hline 16 & $\$ 150,000$ or more & 6800 & 8.10 \\
\hline
\end{tabular}

Another primary variable of importance is educational attainment. This is measured by the question "What is the highest level of school completed" (Codebook 2010: 34) originally this variable allowed for a variety of responses ranging from "less than $1^{\text {st }}$ grade" to "Doctorate Degree". This variable has been recoded into a dummy variable where 1 equals a high school education or less and 0 equates to those who 
have some college or more. The educational variable will also be combined with veteran status to form an interaction term.

Gender serves as the fourth primary independent variable. The original gender variable includes responses for male and female (Codebook 2010: 33). Therefore the gender variable has been dummy coded with women equaling 1 and men equaling 0 . One interaction term was created and involves the variable of veteran status.

Lastly, race serves as the fifth primary independent variable. Previous research has shown the impact of race on economic outcomes, therefore race is included as an independent variable. The unaltered race and ethnicity variables include a large variety of choices for respondents to identify themselves with (Codebook 2010: 35-36). For this research project, race has been recoded into four dummy variables: non-Hispanic White, non-Hispanic Black, Hispanic, and Other. Again, interaction terms have been created between the race / ethnicity variables and the veteran variable.

Marital status was originally coded with the following categories: married spouse present, married - spouse absent, widowed, divorced, separated, and never married (Codebook 2010; 31). For inclusion in this research this variable has been recoded into a dummy variable with unmarried equaling 1 . This variable serves as a control variable in regression analyses.

Disability status is another independent variable of concern for this research. The disability variable is dummy coded, 1 for positive and 0 for negative. The specific 
question utilized for this variable is, "Does this person have any of these disability conditions?" (Codebook 2010: 233) from the CPS which refers to a series of questions concerning various disabilities. Specifically six questions ask respondents whether or not they experience difficulties, caused by a physical, mental, or emotional condition, when performing common tasks such as: having difficulty hearing, having difficulty seeing even with glasses, having difficulty with cognition, having difficulty walking or climbing stairs, having difficulty dressing or bathing, and having difficulty going out to run errands. These questions measure a respondent's ability to perform activities of daily living (ADLs); difficulties with ADLs generally indicate some measure of disability. This variable serves as a control variable in regression analyses.

Employment status has been included in this research project to elucidate differences that exist between the household incomes of those who are employed and those who are unemployed. This variable was originally coded with the categories of employed, unemployed, not in the labor force (discouraged), and not in the labor force (other) (Codebook 2010: 55). This was re-coded into a dichotomous variable with employed equaling 0 and all other categories equaling 1 . This variable serves as a control variable in regression analyses.

Household size, measured by the number of people within the household has been included as a variable for use in regression analyses. This variable, originally a scale from 1 to 16 (Codebook 2010: 11), has been top-coded at 6 . This variable is 
present to control for the effects of a growing household on household income. This variable serves as a control variable in regression analyses.

The age of respondents, a scale variable, has been included as an independent variable for use in regression analyses (Codebook 2010: 28-9). The age variable only includes those respondents between the ages of 18 and 64. This variable serves as a control variable in regression analyses. The mean household income for each age group was plotted against age to verify a linear relationship between these variables. The line of best fit drawn for this data very nearly represents the data at all levels, with some slight under and over representation at around 20 years of age. The mean, median, and skew for the average household income by age are 10.9, 11.1, and -1.1 respectively. This describes a linear relationship between the age and income variables, thus accounting for the linearity assumption of OLS regressions.

One variable that accounts for differences among veterans that has been included is the length (in years) of active duty service (Codebook 2010: 249-250). For the variable of length of service, those who have not served in the military have been coded as 0 , since they lack any military service experience. The variable of length of active duty service is an ordinal variable coded with the following categories: 1 ) less than six months, 2) six months to two years, 3) two to three years, 4) three to four years, 5) five to nine years, 6) ten to fourteen years, 7) fifteen to nineteen years, 8) twenty years or more. 749 respondents who answered yes to being a veteran of active 
duty were listed as not in universe for the length of service variable; these respondents were recoded as having experienced 1 for length of service to show that they have served but have not served for an extended period; these same respondents were disregarded from the combat veteran analyses. This variable serves as a control variable in regression analyses.

A second variable that illuminates differences between veterans is the amount of years separated from military service (Codebook 2010: 245-7). For the variable of years of separation, those who have not served in the military have been coded as 0 , since they lack any military service experience. For those respondents who have served in the military, but have a 0 for years of separation, the response has been recoded as 0.1 to provide a difference between those who have served and those who have not. The remaining respondents remained unchanged. This variable was subtracted from the year of the survey, 2010, to obtain the amount of time variable shave been separated from the military. The variable of years separated has a range of 0 to 47 years. This variable serves as a control variable in regression analyses.

The last variables included concern the era in which a veteran has served (Codebook 2010: 221-2). Due to the age restrictions, respondents' service eras are limited to no earlier than 1955 . This variable has been recoded into multiple dummy variables with the following equaling 1 and all else equaling 0: the period of 1955 to 
1964, Vietnam, 1975 to 1990,1990 to 2001 , and post $9 / 11$. This variable serves as a control variable in regression analyses.

In order to estimate the effect of veteran status on household income this study utilizes OLS regressions. Two sets of OLS regressions are analyzed, with the first two regarding the sample of veterans versus all non-veterans and the second set concerning combat veterans versus non-combat veterans. Each model progressively introduces relevant variables to isolate the effects of statuses to further elucidate the effects of veteran status. Once all variables have been introduced, the following table analyzes the effects of interaction terms on household income. The interaction terms of gender, race, and education by veteran and later combat veteran status have been chosen because of their theoretical importance in relation to economic potentials. These interaction terms will add to the current theoretical understandings of human and social capital, life course, and status attainment perspectives that have been presented previously. 


\section{Results}

\section{Excluded}

Table 2a: Descriptive Statistics of Included and Excluded Respondents (weighted \%)

\begin{tabular}{llll} 
& Included & Excluded & T Test Sig. \\
\hline Veteran & $4982(6.42)$ & $4757(21.81)$ & $* * *$ \\
Female & $42946(50.71)$ & $26882(54.84)$ & $* *$ \\
Non-Hispanic White & $57976(65.58)$ & $35786(75.49)$ & $* * *$ \\
Non-Hispanic Black & $8285(12.13)$ & $5288(9.71)$ & $* * *$ \\
Hispanic & $10647(15.33)$ & $7635(9.60)$ & $* * *$ \\
Other & $6092(6.96)$ & $21996(5.20)$ & $* * *$ \\
Lt HS or HS & $34188(41.80)$ & $16375(62.97)$ & $* * *$ \\
Unmarried & $37547(46.29)$ & $13943(52.55)$ & $* * *$ \\
Unemployed & $54189(30.47)$ & $20316(81.43)$ & \\
$55-64$ & $12(0.01)$ & $1314(5.51)$ & $* * *$ \\
Vietnam & $1973(2.25)$ & $1041(5.02)$ & $* * *$ \\
$75-90$ & $1582(2.12)$ & $221(1.26)$ & $* * *$ \\
$90-01$ & $855(1.15)$ & $127(0.75)$ & $* * *$ \\
Post 9/11 & $560(0.89)$ & $66(0.37)$ & $* * *$ \\
Disability & $6418(7.44)$ & $5833(24.26)$ & $* * *$ \\
\hline Mean/ std. deviation & Weighted & & T Test Sig. \\
\hline Household Income & $10.88 / 4.83$ & $9.71 / 2.62$ & $* * *$ \\
Age & $40.51 / 16.12$ & $62.52 / 15.5$ & $* * *$ \\
Years since separated & $1.27 / 7.44$ & $7.09 / 12.12$ & $* * *$ \\
Length of service & $0.22 / 1.19$ & $0.67 / 1.81$ & $* * *$ \\
Household number & $3.15 / 1.74$ & $2.47 / 0.93$ & $* * *$ \\
\hline P & & & \\
\hline
\end{tabular}

$* \mathrm{p}<.05 * * \mathrm{p}<.01 * * * \mathrm{p}<.001$

Respondents were excluded from this research for one of three reasons: 1) they were outside of the standard working ages of 18 to 64,2 ) a member of the household was in the active duty military, and 3) they were missing from any variable included in the regression analyses. A comparison of those included in this research to those who 
were not was performed in Table 2a; these results are reported using weighted proportions. $21.81 \%$ of respondents excluded from this research were veterans as compared to $6.42 \%$ of the sample included. $54.84 \%$ of the excluded respondents were female and have the following racial composition: Non-Hispanic White $75.49 \%$, NonHispanic Black 9.71\%, Hispanic 9.60\% and Other racial backgrounds 5.20\%. Respondents excluded tended to have a lower education attainment, $62.97 \%$. Respondents excluded also tended to be unmarried, $52.55 \% .81 .43 \%$ of the excluded respondents were unemployed and $24.26 \%$ were disabled. The household income of respondents tended to be lower than that of those included in this project with a mean of 9.71. Each of these differences noted, excepting those obtained for the unemployed variable, received significant T-test results at $p<.01$ level. As noted from these descriptive statistics, those who were excluded from this project tended to have lower levels of household income and poorer economic performance as noted by increased rates of disability. Furthermore, these respondents were more likely to be unmarried and have lower levels of education than those included in this research. Analyses obtained from the included sample will therefore be conservative, with an understanding that these results may not accurately represent those not of working age or those who are not performing strongly in the economic sphere. It must be noted that the mean age of those not included, $\sim 62$, represents those respondents who did not 
meet selection criteria; therefore this shows that the majority of excluded respondents are those who are of retired ages.

\section{Descriptive Statistics}

Table $2 \mathrm{~b}$ provides the descriptive statistics of the sample used in this research.

In this sample, veterans differ from non-veterans in a few notable ways. Female

respondents make up $53.47 \%$ and $10.54 \%$ of the non-veteran and veteran categories

Table 2b: Descriptive Statistics of Sample

(weighted \%)

\begin{tabular}{|c|c|c|c|}
\hline & Non-Veteran & Veteran & T Test Sig \\
\hline Female & 42490 (53.47) & $456(10.54)$ & $* * *$ \\
\hline Non-Hispanic White & $53985(64.81)$ & 3991 (76.77) & $* * *$ \\
\hline Non-Hispanic Black & 7793 (12.11) & $492(12.47)$ & \\
\hline Hispanic & 10400 (15.94) & $247(6.35)$ & $* * *$ \\
\hline Other & $5840(7.14)$ & $252(4.41)$ & $* * *$ \\
\hline Lt HS or HS & 32466 (42.37) & 1722 (33.45) & $* * *$ \\
\hline Unmarried & $35868(47.02)$ & 1679 (35.54) & $* * *$ \\
\hline Unemployed & $22724(30.53)$ & 1465 (29.63) & \\
\hline $55-64$ & $\mathrm{n} / \mathrm{a}$ & $12(0.23)$ & $\mathrm{n} / \mathrm{a}$ \\
\hline Vietnam & $\mathrm{n} / \mathrm{a}$ & 1973 (34.98) & $\mathrm{n} / \mathrm{a}$ \\
\hline $75-90$ & $\mathrm{n} / \mathrm{a}$ & 1582 (32.99) & $\mathrm{n} / \mathrm{a}$ \\
\hline $90-01$ & $\mathrm{n} / \mathrm{a}$ & 855 (17.96) & $\mathrm{n} / \mathrm{a}$ \\
\hline Post 9/11 & $\mathrm{n} / \mathrm{a}$ & $560(13.86)$ & $\mathrm{n} / \mathrm{a}$ \\
\hline Disability & 5749 (7.09) & $669(12.51)$ & $* * *$ \\
\hline Mean/ std. deviation & Weighted & & \\
\hline Household Income & $10.84 / 4.84$ & $11.46 / 4.54$ & $* * *$ \\
\hline Age & $39.91 / 15.95$ & 49.19 / 14.53 & $* * *$ \\
\hline Years separated & $\mathrm{N} / \mathrm{A}$ & $19.80 / 18.65$ & $\mathrm{n} / \mathrm{a}$ \\
\hline Length of service & $\mathrm{N} / \mathrm{A}$ & $3.49 / 2.38$ & $\mathrm{n} / \mathrm{a}$ \\
\hline Household number & 3.18 / 1.74 & $2.72 / 1.68$ & $* * *$ \\
\hline
\end{tabular}

$* \mathrm{p}<.05 * * \mathrm{p}<.01 * * * \mathrm{p}<.001$

T-Test Significance is for unequal variances.

respectively. This difference is expected since women tend to have decreased levels of service in the military. Veterans have a higher percentage of Non-Hispanic White, 
$76.77 \%$ versus $64.81 \%$, and a lower percentage of Hispanic respondents as compared to non-veterans; Veterans are nearly just as likely as non-veterans to be non-Hispanic Black and less likely to belong to the Other racial category. Veterans have a higher percentage of respondents with more than a high school education, with $42.37 \%$ of non-veterans and $33.45 \%$ of veterans achieving less than high school or high school equivalency. Veterans appear to be on average older than non-veterans with a mean age of 49.19 as compared to that of non-veterans of 39.91. The age variable has been previously plotted against the dependent variable of household income and the line of best fit

Table 3: Descriptive Statistics of Veterans (weighted \%)

\begin{tabular}{|c|c|c|c|}
\hline & Non-Combat Veteran & Combat Veteran & T Test Sig. \\
\hline Female & $326(13.65)$ & $68(5.24)$ & $* * *$ \\
\hline Non-Hispanic White & $2229(78.41)$ & $1167(76.37)$ & $*$ \\
\hline Non-Hispanic Black & 249 (11.99) & $151(12.25)$ & \\
\hline Hispanic & $116(5.67)$ & $79(6.82)$ & \\
\hline Other & $129(3.93)$ & $77(4.56)$ & \\
\hline Lt HS or HS & $942(33.27)$ & $483(31.71)$ & \\
\hline Unmarried & $928(36.53)$ & $486(34.41)$ & \\
\hline Unemployed & $742(27.49)$ & $508(34.43)$ & $* * *$ \\
\hline $55-64$ & $8(0.21)$ & $2(0.21)$ & \\
\hline Vietnam & 967 (31.12) & $730(44.27)$ & $* * *$ \\
\hline $75-90$ & $1073(40.70)$ & $244(17.91)$ & $* * *$ \\
\hline $90-01$ & 464 (18.19) & $248(17.32)$ & \\
\hline Post 9/11 & $211(9.78)$ & $250(20.29)$ & $* * *$ \\
\hline Disability & 341 (12.03) & $252(15.16)$ & $* * *$ \\
\hline mean / std. deviation & Weighted & & \\
\hline Household Income & $11.42 / 4.62$ & $11.58 / 4.30$ & \\
\hline Age & 49.32 / 13.46 & 49.50 / 16.02 & \\
\hline Years separated & $24.58 / 14.76$ & 22.11 / 18.94 & $* * *$ \\
\hline Length of service & 3.67 / 1.97 & $4.47 / 2.24$ & $* * *$ \\
\hline Household number & $2.68 / 1.64$ & 2.69 / 1.69 & \\
\hline
\end{tabular}

$* \mathrm{p}<.05 * * \mathrm{p}<.01 * * * \mathrm{p}<.001$

T-Test Significance is for unequal variances. 
accurately represents the mean earnings for every age. Furthermore, veterans are more likely to be married with $47.02 \%$ of non-veterans and $35.54 \%$ of veterans being unmarried. The average family size for veteran households is 2.72 as opposed to 3.18 for non-veterans.

Table 3 provides the descriptive statistics for the veteran sample used in this project. There are a few notable differences that exist between combat and noncombat veterans within this sample. Where the non-combat veterans are $13.65 \%$ female, combat veterans are only $5.24 \%$ female. $78.41 \%$ of combat veterans are nonHispanic White as compared to $76.37 \%$ of non-combat veterans. Combat veterans as compared to non-combat veterans are more likely to be unemployed with $34.43 \%$ and $27.49 \%$ respectively. Combat veterans are also more likely to be disabled with $15.16 \%$ as compared to non-combat veterans at $12.03 \%$. Non-combat veterans are slightly more likely to be unmarried at $36.53 \%$ as compared to combat veterans at $34.41 \%$, however t-test results are non-significant. Combat veterans have a slightly shorter average separation time from the military but the average length of service is longer than non-combat veterans.

\section{The Effect of Veteran Status on Income}

Table 4 shows the effects of control variables and veteran status on household income. In model one, the veteran status coefficient of $0.625(p<.001)$ is positive and 
significant. However with the additional of the demographic variables of gender, race, educational attainment, and age in Model 2 the veteran coefficient is no longer significant indicating that after controlling for demographic differences veterans do not earn more than non-veterans. This indicates a possible spurious connection concerning the effect of veteran status on household income; the demographic variables account for the impact of veteran status on household income rather than veteran status itself. The results in Model 2 support the understanding that women, racial minorities and those with lower educational attainment have lower levels of household income as compared to the non-minority constant; these minority demographic variables remain negative in all subsequent models in Table 4. As expected, age is significantly and positively related to earnings. For the remaining models in table 4, veteran status remains non-significant. Model 2 accounts for $13.63 \%$ of the variation of the dependent variable as noted by the $\mathrm{R}^{2}$ term.

Model 3 of Table 4 introduces the effects of being unmarried and unemployed to the previous model. The coefficients for being unmarried and unemployed are $-1.827(p<.001)$ and $-1.771(p<.001)$ respectively indicating the negative effects of these statuses on household income. With the addition of the unmarried and unemployed variables the negative impacts of being a women, Non-Hispanic Black and having lower educational attainment have diminished; the unmarried and unemployed variables act as mediators. As noted by Mirowsky (1999), "...a mediator results from the 
hypothetical cause but precedes the apparent consequence" (111). In this case it is likely that the effects of gender, race, and education come prior to the effects of being 
Table 4: OLS Regression of Household Income on Veteran Status

\begin{tabular}{|c|c|c|c|c|c|}
\hline & M 1 & M 2 & M 3 & M 4 & M 5 \\
\hline Constant & $\begin{array}{c}10.836 * * * \\
(0.014)\end{array}$ & $\begin{array}{c}11.773 * * * \\
(0.047)\end{array}$ & $\begin{array}{c}13.760 * * * \\
(0.051)\end{array}$ & $\begin{array}{c}13.747 * * * \\
(0.051)\end{array}$ & $\begin{array}{c}11.286 * * * \\
(0.068)\end{array}$ \\
\hline Veteran & $\begin{array}{c}0.625^{* * *} \\
(0.056)\end{array}$ & $\begin{array}{l}-0.037 \\
(0.055)\end{array}$ & $\begin{array}{c}0.083 \\
(0.052)\end{array}$ & $\begin{array}{l}-0.185 \\
(0.144)\end{array}$ & $\begin{array}{l}-0.247 \\
(0.141)\end{array}$ \\
\hline \multicolumn{6}{|l|}{ Demographics } \\
\hline Female (ref. Male) & & $\begin{array}{c}-0.370 * * * \\
(0.026)\end{array}$ & $\begin{array}{c}-0.137 * * * \\
(0.025)\end{array}$ & $\begin{array}{c}-0.138 * * * \\
(0.025)\end{array}$ & $\begin{array}{c}-0.168 * * * \\
(0.025)\end{array}$ \\
\hline \multicolumn{6}{|l|}{ Race (Ref. Non-Hispanic White) } \\
\hline $\begin{array}{l}\text { Non-Hispanic } \\
\text { Black }\end{array}$ & & $\begin{array}{c}-2.005^{* * *} \\
(0.040)\end{array}$ & $\begin{array}{c}-1.478 * * * \\
(0.039)\end{array}$ & $\begin{array}{c}-1.484 * * * \\
(0.039)\end{array}$ & $\begin{array}{c}-1.545^{* * *} \\
(0.038)\end{array}$ \\
\hline Hispanic & & $\begin{array}{c}-1.423^{* * *} \\
(0.038)\end{array}$ & $\begin{array}{c}-1.445^{* * *} \\
(0.035)\end{array}$ & $\begin{array}{c}-1.447^{* * *} \\
(0.035)\end{array}$ & $\begin{array}{c}-1.796 * * * \\
(0.035)\end{array}$ \\
\hline Other & & $\begin{array}{c}-0.433^{* * *} \\
(0.051)\end{array}$ & $\begin{array}{c}-0.368 * * * \\
(0.049)\end{array}$ & $\begin{array}{c}-0.368 * * * \\
(0.049)\end{array}$ & $\begin{array}{c}-0.583^{* * *} \\
(0.048)\end{array}$ \\
\hline $\begin{array}{l}\text { Lt HS or HS (Ref. More than High } \\
\text { School) }\end{array}$ & & $\begin{array}{c}-2.223^{* * *} \\
(0.027)\end{array}$ & $\begin{array}{c}-1.865^{* * *} \\
(0.026)\end{array}$ & $\begin{array}{c}-1.860 * * * \\
(0.026)\end{array}$ & $\begin{array}{c}-1.934 * * * \\
(0.025)\end{array}$ \\
\hline Age & & $\begin{array}{c}0.018 * * * \\
(0.001)\end{array}$ & $\begin{array}{c}-0.006 * * * \\
(0.001)\end{array}$ & $\begin{array}{c}-0.005^{* * *} \\
(0.001)\end{array}$ & $\begin{array}{c}0.018^{* * *} \\
(0.001)\end{array}$ \\
\hline Unmarried (Ref. Married) & & & $\begin{array}{c}-1.827 * * * \\
(0.026)\end{array}$ & $\begin{array}{c}-1.823 * * * \\
(0.026)\end{array}$ & $\begin{array}{c}-1.288 * * * \\
(0.028)\end{array}$ \\
\hline Unemployed & & & $\begin{array}{c}-1.771 * * * \\
(0.027)\end{array}$ & $\begin{array}{c}-1.766 * * * \\
(0.027)\end{array}$ & $\begin{array}{c}-1.625 * * * \\
(0.027)\end{array}$ \\
\hline Years separated from the military & & & & $\begin{array}{l}-0.008 \\
(0.004)\end{array}$ & $\begin{array}{l}-0.002 \\
(0.004)\end{array}$ \\
\hline Length of service in the military & & & & $\begin{array}{c}0.122 * * * \\
(0.026)\end{array}$ & $\begin{array}{c}0.117 * * * \\
(0.025)\end{array}$ \\
\hline
\end{tabular}


Table 4: OLS Regression of Household Income on Veteran Status Cont.

M 1 M 2

M 3

M 4

M 5

Era of Service (Ref. 75-90)

$55-64$

$-2.273^{*}$

(1.017)

$-2.186^{*}$

Vietnam

0.055

(0.130)

(0.995)

$90-01$

0.154

(0.145)

(0.127)

Post $9 / 11$

$-0.134$

0.124

๙ి Disability

(0.167)

$(0.142)$
0.053

(0.164)

$-1.507^{* * *}$

(0.048)

Household size

$0.464 * * *$

(0.009)

\begin{tabular}{lllll}
\hline $\mathrm{R}^{2}$ & 0.0015 & 0.1363 & 0.2280 & 0.2283 \\
Adj. $\mathrm{R}^{2}$ & 0.0015 & 0.1362 & 0.2279 & 0.2282 \\
\hline
\end{tabular}

Source: Current Population Survey July 2010, Veterans Supplement. Note: Standard error in parentheses. $\mathrm{N}=83000$.

$* \mathrm{p}<.05 * * \mathrm{p}<.01 * * * \mathrm{p}<.001$ 
unmarried and unemployed which then impact household income. Furthermore, the age coefficient has changed from a significant positive effect on household income to that of a significant negative effect. This model accounts for $22.80 \%$ of the variation of the dependent variable as noted by the $\mathrm{R}^{2}$ term.

In Model 4 the variables of years since separating from the military, length of service, and era of service are included. Like the demographic variables, the unmarried and unemployed coefficients remain negative and significant. In this Model, the length of service is positively correlated with household income with a coefficient of 0.122 $(p<.001)$. Of the four eras of service included in this model, only the period from 1955 to 1964 is statistically significant. Generally this would indicate that veterans from this time period experience a negative impact on household income as compared to veterans from the reference category of 1975 to 1990, however because of the small number of respondents in this category these results may not be generalizable. As noted, the remaining era of service coefficients are non-significant. In this model the age coefficient has switched from negative to positive. This model accounts for $22.83 \%$ of the variation of the dependent variable as noted by the $R^{2}$ term.

The final Model for Table 4 adds the variables of having a disability and household size. With the inclusion of the disability and household size terms, the demographic variable coefficients have all become slightly more negative from the previous model. This indicates that the disability and household size variables act as 
suppressors for the demographic variables. From the previous Model, the years since separation variable has become non-significant indicating that the previous negative effect on household income was spurious and due instead to disability and household size. Again, the length of service and 1955 to 1964 era of service variables remain significant at $0.117(p<.001)$ and $-2.186(p<.05)$ respectively; the remaining era of service variables remain non-significant. Lastly, the variables for disability and household number are $-1.507(p<.001)$ and $0.464(p<.001)$ respectively. The disability coefficient indicates the negative effect of disability on household income. The household number variable indicates that for every one unit increase in household size, up to 6 people, there is a corresponding increase in household income by 0.464 units. This model accounts for $26.05 \%$ of the variation of the dependent variable as noted by the $\mathrm{R}^{2}$ term. Table 4 examined the impact of veteran status on household income controlling for the variables utilized in this study. In Model 1 veteran status was found to have a positive effect on household income. However, after controlling for race, gender, education, and age the effect of veteran status became non-significant. This indicates that veteran status in general does not affect household income. Rather it is that veterans tend to be non-Hispanic White, men, with higher levels of education, and of a more appropriate age which all positively impacts household income. 


\section{Age in Table 4}

In Table 4 the Age coefficient experiences positive and negative changes in relation to the addition of variables in models. In Model 3 being unmarried and unemployed are introduced, this causes a change in the coefficient of the age variable from a positive to a negative. The correlation between age and being unmarried is -0.347. The correlation between age and being unmarried indicates that older respondents are more likely to be married. In Model 4, military service characteristics are included and the age coefficient changes from -0.006 to -0.005 . The final Model of Table 4 introduces the effects of being disabled and household size; the age coefficient once again becomes positive and similar to the value seen in Model 2. A correlation of $0.156(p<.001)$ exists between age and disability and $-0.263(p<.001)$ between age and household size. As respondents of this sample get older they are more likely to be disabled which has a negative effect on household income. With the introduction of the disabled variable, the age coefficient becomes positive indicating the negative effects previously seen in age were due to the disabled variable.

\section{Multicollinearity}

With the addition of the service characteristic variables in Model 4 of Table 4 the tolerance for the veteran coefficient becomes 0.099 which falls just below acceptable levels for tolerance; prior to this model the veteran coefficient tolerance level was consistently above 0.8 . This indicates that multicollinearity may be occurring with other 
variables in the model. Specifically the service related variables of years separated from the military and length of military service may be accounting for the possible collinearity problems; these variables are related to both the variables of age and era of service. Three variables were identified, due to strong correlations with the years separated variable: the veteran variable has a correlation coefficient of $0.79(p<.001)$, the length of service variable has a correlation coefficient of $0.71(p<.001)$, and the Vietnam era variable has a correlation coefficient of $0.74(p<.001)$.

With the removal of the years separated from the military variable, the veteran coefficient becomes negative and significant from Model 4 onward with tolerance levels greater than 0.12. This indicates a change which occurs in Table 5 Model 1 in which the veteran coefficient becomes negative and significant. Despite this change the female veteran interaction term remains non-significant in Table 5 Model 1. Little to no change is experienced in the remaining variables in all subsequent models which is verified by similar regression coefficients currently present in Table 5 Model 4.

Despite some of the tolerance levels, the variables included in the modeling structure presented in this study have been identified by previous research as vitally important in identifying differences which account for differences in veteran economic outcomes. Furthermore the coding of the service characteristic variables, specifically the years separated and length of service, may account for some of this problem; the high correlations between the veteran coefficient and these two variables provides 
evidence of this. Therefore, since the regression coefficients of nearly all variables in every model change very slightly, the years separated from the military variable, is included in these results.

\section{Veteran Status and Interaction Terms}

Table 5 Model 1 introduces the effect of the interaction term of being a female veteran to the final Model of Table 4. The regression constant coefficient in this and subsequent Models of Table 5 represents those respondents who are non-disabled males, Non-Hispanic White, non-veterans who are married, employed, with higher levels of education with no service related characteristics, and who are from smaller households. In this Model, both the veteran coefficient representing male veterans and the subsequent female veteran interaction term are non-significant. The variables from Model 4 of Table 4 remain unchanged with the addition of the interaction term. This

model accounts for $26.05 \%$ of the variation of the dependent variable as noted by the $\mathrm{R}^{2}$ term.

Model 2 of Table 5 removes the previous interaction term and introduces the effect of race and ethnicity paired with veteran status on household income. The veteran coefficient of $-0.549(p<.01)$ represents those veterans who are Non-Hispanic White; Non-Hispanic White veterans experience a negative impact on household income when controlling for the remaining variables in this Model. Of the interaction terms, 
Table 5: OLS Regression of Household Income on Veteran Status with Interaction Terms

\begin{tabular}{|c|c|c|c|c|}
\hline & M 1 & M 2 & M 3 & M 4 \\
\hline \multirow[t]{2}{*}{ Constant } & $11.287^{* * *}$ & $11.303 * * *$ & $11.294 * * *$ & $11.313^{* * *}$ \\
\hline & $(0.068)$ & $(0.068)$ & $(0.068)$ & $(0.068)$ \\
\hline \multirow[t]{2}{*}{ Veteran } & -0.258 & $-0.549 * *$ & $-0.504 * *$ & $-0.828 * * *$ \\
\hline & $(0.143)$ & $(0.145)$ & $(0.147)$ & $(0.154)$ \\
\hline \multicolumn{5}{|l|}{ Demographics } \\
\hline \multirow[t]{2}{*}{ Female (ref. Male) } & $-0.170 * * *$ & $-0.167 * * *$ & $-0.169 * * *$ & $-0.172 * * *$ \\
\hline & $(0.025)$ & $(0.025)$ & $(0.025)$ & $(0.025)$ \\
\hline \multicolumn{5}{|l|}{ Race (Ref. Non-Hispanic White) } \\
\hline Non-Hispanic & $-1.545^{* * *}$ & $-1.606 * * *$ & $-1.542 * * *$ & $-1.601 * * *$ \\
\hline Black & $(0.038)$ & $(0.039)$ & $(0.038)$ & $(0.039)$ \\
\hline \multirow[t]{2}{*}{ Hispanic } & $-1.796 * * *$ & $-1.859 * * *$ & $-1.786 * * *$ & $-1.849 * * *$ \\
\hline & $(0.035)$ & $(0.036)$ & $(0.035)$ & $(0.036)$ \\
\hline \multirow[t]{2}{*}{ Other } & $-0.583 * * *$ & $-0.601 * * *$ & $-0.584 * * *$ & $-0.602 * * *$ \\
\hline & $(0.048)$ & $(0.049)$ & $(0.048)$ & $(0.049)$ \\
\hline Lt HS or HS (Ref. More than High & $-1.934 * * *$ & $-1.924 * * *$ & $-1.972 * * *$ & $-1.962 * * *$ \\
\hline School) & $(0.025)$ & $(0.025)$ & $(0.026)$ & $(0.026)$ \\
\hline \multirow[t]{2}{*}{ Age } & $0.018 * * *$ & $0.018 * * *$ & $0.018 * * *$ & $0.018 * * *$ \\
\hline & $(0.001)$ & $(0.001)$ & $(0.001)$ & $(0.001)$ \\
\hline \multirow[t]{2}{*}{ Unmarried (Ref. Married) } & $-1.289 * * *$ & $-1.289 * * *$ & $-1.287 * * *$ & $-1.288 * * *$ \\
\hline & $(0.028)$ & $(0.027)$ & $(0.028)$ & $(0.027)$ \\
\hline \multirow[t]{2}{*}{ Unemployed } & $-1.625 * * *$ & $-1.627 * * *$ & $-1.623 * * *$ & $-1.624 * * *$ \\
\hline & $(0.027)$ & $(0.027)$ & $(0.027)$ & $(0.027)$ \\
\hline \multirow[t]{2}{*}{ Years separated from the military } & -0.002 & -0.001 & -0.003 & -0.0003 \\
\hline & $(0.004)$ & $(0.004)$ & $(0.004)$ & $(0.004)$ \\
\hline \multirow[t]{2}{*}{ Length of service in the military } & $0.117 * * *$ & $0.109 * * *$ & $0.133^{* * *}$ & $0.126^{* * *}$ \\
\hline & $(0.025)$ & $(0.025)$ & $(0.025)$ & $(0.026)$ \\
\hline \multicolumn{5}{|l|}{ Era of Service (Ref. 75-90) } \\
\hline \multirow[t]{2}{*}{$55-64$} & $-2.177^{*}$ & $-2.306^{*}$ & $-2.356^{*}$ & $-2.454^{*}$ \\
\hline & $(0.996)$ & (0.995) & $(0.996)$ & $(0.996)$ \\
\hline
\end{tabular}




\begin{tabular}{|c|c|c|c|c|}
\hline & M 1 & M 2 & M 3 & M 4 \\
\hline \multirow{2}{*}{ Vietnam } & 0.076 & 0.147 & 0.086 & 0.177 \\
\hline & $(0.128)$ & $(0.127)$ & $(0.127)$ & $(0.128)$ \\
\hline \multicolumn{5}{|l|}{ Era of Service Cont. } \\
\hline \multirow[t]{2}{*}{$90-01$} & 0.122 & 0.150 & 0.164 & 0.186 \\
\hline & $(0.142)$ & $(0.142)$ & $(0.142)$ & $(0.143)$ \\
\hline \multirow[t]{2}{*}{ Post 9/11 } & 0.052 & 0.039 & 0.077 & 0.058 \\
\hline & (0.164) & $(0.164)$ & $(0.164)$ & $(0.165)$ \\
\hline \multirow[t]{2}{*}{ Disability } & $-1.507 * * *$ & $-1.507 * * *$ & $-1.508 * * *$ & $-1.508 * * *$ \\
\hline & $(0.048)$ & $(0.048)$ & $(0.048)$ & $(0.048)$ \\
\hline \multirow[t]{2}{*}{ Household size } & $0.464 * * *$ & $0.466 * * *$ & $0.465^{* * *}$ & $0.467^{* * *}$ \\
\hline & (0.009) & (0.009) & (0.009) & $(0.009)$ \\
\hline \multicolumn{5}{|l|}{ Interaction Effects } \\
\hline \multirow[t]{2}{*}{ Female Veteran } & 0.063 & & & 0.157 \\
\hline & (0.157) & & & $(0.158)$ \\
\hline \multirow[t]{2}{*}{ NHB Veteran } & & $0.893 * * *$ & & $0.872 * * *$ \\
\hline & & $(0.150)$ & & $(0.150)$ \\
\hline \multirow[t]{2}{*}{ HIS Veteran } & & $1.803 * * *$ & & $1.799 * * *$ \\
\hline & & (0.198) & & $(0.198)$ \\
\hline \multirow[t]{2}{*}{ OTH Veteran } & & 0.222 & & 0.249 \\
\hline & & $(0.235)$ & & $(0.235)$ \\
\hline \multirow{2}{*}{ Lt HS or HS Veteran } & & & $0.622 * * *$ & $0.612 * * *$ \\
\hline & & & $(0.104)$ & $(0.104)$ \\
\hline $\mathrm{R}^{2}$ & 0.2605 & 0.2615 & 0.2608 & 0.2618 \\
\hline Adj. $R^{2}$ & 0.2604 & 0.2613 & 0.2607 & 0.2616 \\
\hline
\end{tabular}

Source: Current Population Survey July 2010, Veterans Supplement. Note: Standard error in parentheses. $\mathrm{N}=83000$.

$* p<.05 * * p<.01 * * * p<.001$

${ }^{a}$ Non-Hispanic Black, ${ }^{b}$ Hispanic, ${ }^{c}$ Other racial categories, ${ }^{d}$ Less than High school or High school 
only the Non-Hispanic Black veteran and Hispanic veteran coefficients are significant at $0.893(p<.001)$ and $1.803(p<.001)$ respectively. This indicates that these two groups experience a positive effect on household income when controlling for the remaining variables in this model. Those veterans who are categorized as belonging to other racial groups have a non-significant regression coefficient and do not differ from the group of respondents represented by the regression constant. This model accounts for $26.15 \%$ of the variation of the dependent variable as noted by the $R^{2}$ term.

Model 3 of Table 5 removes the previous interaction terms and introduces the interaction term of lower educational attainment and veteran status. The veteran coefficient of $-0.504(p<.01)$ in this Model represents those veterans with higher levels of education attainment; this indicates a negative impact on household income as compared to the group represented by the regression constant. The regression coefficient for veterans with lower levels of educational attainment is $0.622(p<.001)$ which indicates an increase of household income as compared to the group of respondents represented by the regression constant. The remaining variables in this model remain relatively unchanged from previous models. This model accounts for $26.08 \%$ of the variation of the dependent variable as noted by the $\mathrm{R}^{2}$ term.

The final Model of Table 5 shows the effects of all interaction terms simultaneously. As in previous models, the Non-Hispanic Black, Hispanic, and low educational attainment veteran interaction terms remain unchanged, positive and 
significant. This verifies that it is unlikely that the interaction terms are interacting with another to alter the results. This model accounts for $26.18 \%$ of the variation of the dependent variable as noted by the $\mathrm{R}^{2}$ term.

Three outcomes appear in Table 5. With the introduction of the gender interaction term in Model 1, it is apparent that veterans do not differ significantly by gender. In Model 2, the interaction terms of non-Hispanic Black and Hispanic veterans are significant and positive, showing increased earnings as compared to similar nonveterans. In Model 3 the interaction term of education provides similar results, veterans with lower levels of education achieve higher average household incomes as compared to similar non-veterans.

\section{Effect of Combat Veteran Status on Income}

Model 1 of Table 6 shows the effects of the combat veteran variable on household income. Here the coefficient in non-significant. With the addition of the demographic variables in Model 2 the combat veteran coefficient remains nonsignificant. Likewise the coefficients for gender, the racial categories for Hispanic and other, and age are also non-significant. The non-Hispanic Black variable has a coefficient of $-1.170(p<.001)$ indicating a negative effect on household income. The lower educational attainment coefficient is also significant and negative, $-1.708(p<.001)$. This model accounts for $5.96 \%$ of the variation of the dependent variable as noted by the $\mathrm{R}^{2}$ term. 
Table 6: OLS Regression of Household Income on Combat Veteran Status

\begin{tabular}{|c|c|c|c|c|c|}
\hline & M 1 & $\mathrm{M} 2$ & M 3 & M 4 & M 5 \\
\hline Constant & $\begin{array}{c}11.424^{* * *} \\
(0.069)\end{array}$ & $\begin{array}{c}12.168^{* * *} \\
(0.258)\end{array}$ & $\begin{array}{c}13.065^{* * *} \\
(0.241)\end{array}$ & $\begin{array}{c}11.733^{* * *} \\
(0.450)\end{array}$ & $\begin{array}{c}9.972^{* * *} \\
(0.495)\end{array}$ \\
\hline Combat Veteran & $\begin{array}{c}0.153 \\
(0.117)\end{array}$ & $\begin{array}{c}0.118 \\
(0.115)\end{array}$ & $\begin{array}{l}0.251^{*} \\
(0.103)\end{array}$ & $\begin{array}{c}0.119 \\
(0.110)\end{array}$ & $\begin{array}{c}0.145 \\
(0.109)\end{array}$ \\
\hline \multicolumn{6}{|l|}{ Demographics } \\
\hline Female (ref. Male) & & $\begin{array}{l}-0.178 \\
(0.181)\end{array}$ & $\begin{array}{c}0.159 \\
(0.162)\end{array}$ & $\begin{array}{c}0.130 \\
(0.162)\end{array}$ & $\begin{array}{c}0.113 \\
(0.160)\end{array}$ \\
\hline \multicolumn{6}{|l|}{ Race (Ref. Non-Hispanic White) } \\
\hline $\begin{array}{l}\text { Non-Hispanic } \\
\text { Black }\end{array}$ & & $\begin{array}{c}-1.170^{* * *} \\
(0.181)\end{array}$ & $\begin{array}{c}-0.464^{* *} \\
(0.152)\end{array}$ & $\begin{array}{c}-0.570^{* * *} \\
(0.154)\end{array}$ & $\begin{array}{c}-0.604^{* * *} \\
(0.152)\end{array}$ \\
\hline Hispanic & & $\begin{array}{l}-0.086 \\
(0.230)\end{array}$ & $\begin{array}{c}0.173 \\
(0.206)\end{array}$ & $\begin{array}{c}0.151 \\
(0.205)\end{array}$ & $\begin{array}{c}0.008 \\
(0.204)\end{array}$ \\
\hline Other & & $\begin{array}{l}-0.382 \\
(0.274)\end{array}$ & $\begin{array}{l}-0.148 \\
(0.245)\end{array}$ & $\begin{array}{l}-0.164 \\
(0.244)\end{array}$ & $\begin{array}{l}-0.163 \\
(0.242)\end{array}$ \\
\hline $\begin{array}{l}\text { Lt HS or HS (Ref. More than High } \\
\text { School) }\end{array}$ & & $\begin{array}{l}-1.708 * * * \\
(0.116)\end{array}$ & $\begin{array}{c}-1.375^{* * *} \\
(0.105)\end{array}$ & $\begin{array}{c}-1.270^{* * *} \\
(0.106)\end{array}$ & $\begin{array}{c}-1.269 * * * \\
(0.105)\end{array}$ \\
\hline Age & & $\begin{array}{l}0.0001 \\
(0.004)\end{array}$ & $\begin{array}{c}0.006 \\
(0.004)\end{array}$ & $\begin{array}{l}0.037^{* *} \\
(0.012)\end{array}$ & $\begin{array}{c}0.050 * * * \\
(0.011)\end{array}$ \\
\hline Unmarried (Ref. Married) & & & $\begin{array}{c}-2.244 * * * \\
(0.105)\end{array}$ & $\begin{array}{c}-2.183^{* * *} \\
(0.105)\end{array}$ & $\begin{array}{c}-1.717^{* * *} \\
(0.118)\end{array}$ \\
\hline Unemployed & & & $\begin{array}{c}-2.221 * * * \\
(0.111)\end{array}$ & $\begin{array}{c}-2.151^{* * *} \\
(0.112)\end{array}$ & $\begin{array}{c}-1.916^{* * *} \\
(0.115)\end{array}$ \\
\hline Years separated from the military & & & & $\begin{array}{l}-0.024^{*} \\
(0.011)\end{array}$ & $\begin{array}{l}-0.018 \\
(0.011)\end{array}$ \\
\hline Length of service in the military & & & & $\begin{array}{c}0.063 \\
(0.042)\end{array}$ & $\begin{array}{c}0.069 \\
(0.041)\end{array}$ \\
\hline
\end{tabular}


Table 6: OLS Regression of Household Income on Combat Veteran Status Cont.

\begin{tabular}{|c|c|c|c|c|c|}
\hline & M 1 & M 2 & M 3 & M 4 & M 5 \\
\hline \multicolumn{6}{|c|}{ Era of Service (Ref. 75-90) } \\
\hline $55-64$ & & & & $\begin{array}{c}-2.599 * \\
(1.073)\end{array}$ & $\begin{array}{c}-2.752 * * \\
(1.059)\end{array}$ \\
\hline Vietnam & & & & $\begin{array}{l}-0.006 \\
(0.171)\end{array}$ & $\begin{array}{c}0.021 \\
(0.168)\end{array}$ \\
\hline $90-01$ & & & & $\begin{array}{l}0.437^{*} \\
(0.170)\end{array}$ & $\begin{array}{l}0.379 * \\
(0.168)\end{array}$ \\
\hline Post 9/11 & & & & $\begin{array}{c}0.170 \\
(0.238)\end{array}$ & $\begin{array}{c}0.248 \\
(0.234)\end{array}$ \\
\hline Disability & & & & & $\begin{array}{c}-1.167^{* * *} \\
(0.150)\end{array}$ \\
\hline Household size & & & & & $\begin{array}{c}0.334 * * * \\
(0.044)\end{array}$ \\
\hline $\mathrm{R}^{2}$ & 0.0004 & 0.0596 & 0.2448 & 0.2525 & 0.2742 \\
\hline Adj. $R^{2}$ & 0.0002 & 0.0580 & 0.2432 & 0.2498 & 0.2713 \\
\hline
\end{tabular}

Source: Current Population Survey July 2010, Veterans Supplement. Note: Standard error in parentheses. $\mathrm{N}=4197$.

$* \mathrm{p}<.05 * * \mathrm{p}<.01 * * * \mathrm{p}<.001$ 
Model 3 of Table 6 introduces the effects of being unmarried and unemployed. In this model the combat veteran coefficient of $0.251(p<.05)$ becomes significant. This indicates that the variables introduced act as suppressors for the combat veteran coefficient. Weighted correlations between combat veteran status and these two variables: with the unmarried variable the correlation is -0.021 and with the unemployed variable 0.072. Again, the coefficients for the non-Hispanic Black and lower educational attainment variables remain significant, however their effects decrease from the previous model. This indicates that part of the negative effect of the non-Hispanic Black and lower educational attainment variables is due to respondents being unmarried and unemployed. The unmarried coefficient is $-2.244(p<.001)$ indicating a strong negative impact on household income. The unemployed coefficient has a similar negative impact of $-2.221(p<.001)$. This model accounts for $24.48 \%$ of the variation of the dependent variable as noted by the $R^{2}$ term.

Model 4 of Table 6 introduces the effects of years separated from the military, the length of service, and the era of service. With the addition of these variables the combat veteran coefficient is non-significant, indicating that the previous relationship with household income is due instead to the significant variables of years separated and the era of service. The remaining variables from the previous model remain relatively unchanged with the new addition. Of the added variables, only the year separated coefficient of $-0.024(p<.05)$, and the eras of 1955 to 1964 and 1990 to 2001 with 
coefficients of $-2.599(p<.05)$ and $0.437(p<.05)$ respectively are significant. As noted previously, the regression coefficient for the era of ' 55 to '64 is represented by a small number of respondents and is likely not representative. This model accounts for $25.25 \%$ of the variation of the dependent variable as noted by the $R^{2}$ term.

Lastly, Model 5 of Table 6 introduces the effects of having a disability and household size. With the addition of these variables, the regression coefficients of variables from previous models remains relatively unchanged, except for the service era '55 to '64 variable which becomes more significant. Again, the combat veteran variable remains non-significant. The disability coefficient of $-1.167(p<.001)$ is negative and indicates a negative effect on household income. The household number coefficient is similarly significant at $0.334(p<.001)$ but has a positive impact on household income. This model accounts for $27.42 \%$ of the variation of the dependent variable as noted by the $\mathrm{R}^{2}$ term.

In Table 6, combat veterans in general are not found to be significantly different from non-combat veterans except for in Model 3. With the addition of the unmarried and unemployed variables, combat veterans achieve higher levels of household income than non-combat veterans. However this advantage disappears with the introduction of the service related characteristics in Model 4. 


\section{Combat Veteran Status and Interaction Terms}

As with Table 4, Table 7 introduces the interaction terms to the final model in Table 5. Model 1 of Table 6 introduces the effect of the interaction term of female combat veterans. The combat veteran coefficient is non-significant. However, the female combat veteran interaction term of $-0.986(p<.05)$ is significant and indicates a negative impact on household income. This model accounts for $27.53 \%$ of the variation of the dependent variable as noted by the $\mathrm{R}^{2}$ term.

Model 2 of Table 7 introduces the interaction terms of combat veterans who are also within the non-Hispanic Black, Hispanic, and Other categories. The female combat veteran interaction term is not included in this model. The interaction terms from the previous models are not included. The variables from previous models remain relatively unchanged, the combat veteran coefficient remains non-significant. None of the racial interaction terms is significant. This model accounts for $27.44 \%$ of the variation of the dependent variable as noted by the $\mathrm{R}^{2}$ term.

Model 3 of Table 7 introduces the interaction term of lower educational attainment and combat veteran status. The interaction terms from the previous models are not included. The variables from previous models remain relatively unchanged; the combat veteran coefficient remains non-significant. The educational attainment interaction term is non-significant. Due to a lack of changes, this model has the same $\mathrm{R}^{2}$ as the previous model as noted by the $\mathrm{R}^{2}$ term. 
Table 7: OLS Regression of Household Income on Combat Veteran Status with Interaction Terms

\begin{tabular}{|c|c|c|c|c|}
\hline & M 1 & M 2 & M 3 & M 4 \\
\hline \multirow[t]{2}{*}{ Constant } & $9.968 * * *$ & $9.997 * * *$ & $9.952 * * *$ & $9.973 * * *$ \\
\hline & $(0.495)$ & $(0.496)$ & $(0.496)$ & $(0.496)$ \\
\hline \multirow[t]{2}{*}{ Combat Veteran } & 0.212 & 0.108 & 0.201 & 0.241 \\
\hline & $(0.112)$ & $(0.121)$ & $(0.129)$ & $(0.145)$ \\
\hline \multicolumn{5}{|l|}{ Demographics } \\
\hline \multirow[t]{2}{*}{ Female (ref. Male) } & 0.290 & 0.116 & 0.120 & 0.309 \\
\hline & $(0.175)$ & $(0.160)$ & $(0.160)$ & $(0.176)$ \\
\hline \multicolumn{5}{|l|}{ Race (Ref. Non-Hispanic White) } \\
\hline Non-Hispanic & $-0.612 * * *$ & $-0.697 * * *$ & $-0.607 * * *$ & $-0.712 * * *$ \\
\hline Black & $(0.152)$ & $(0.187)$ & $(0.152)$ & $(0.188)$ \\
\hline \multirow[t]{2}{*}{ Hispanic } & -0.007 & 0.037 & 0.012 & 0.040 \\
\hline & $(0.204)$ & $(0.259)$ & $(0.204)$ & $(0.259)$ \\
\hline \multirow[t]{2}{*}{ Other } & -0.159 & -0.266 & -0.159 & -0.271 \\
\hline & $(0.242)$ & $(0.307)$ & $(0.242)$ & $(0.307)$ \\
\hline Lt HS or HS (Ref. More than High & $-1.262 * * *$ & $-1.266 * * *$ & $-1.211 * * *$ & $-1.194 * * *$ \\
\hline School) & $(0.105)$ & $(0.105)$ & $(0.128)$ & $(0.128)$ \\
\hline \multirow[t]{2}{*}{ Age } & $0.050 * * *$ & $0.049 * * *$ & $0.050 * * *$ & $0.050 * * *$ \\
\hline & $(0.011)$ & $(0.012)$ & $(0.011)$ & $(0.011)$ \\
\hline \multirow[t]{2}{*}{ Unmarried (Ref. Married) } & $-1.718 * * *$ & $-1.713^{* * *}$ & $-1.717^{* * *}$ & $-1.715^{* * *}$ \\
\hline & $(0.118)$ & $(0.118)$ & $(0.118)$ & $(0.118)$ \\
\hline \multirow[t]{2}{*}{ Unemployed } & $-1.918 * * *$ & $-1.914 * * *$ & $-1.919 * * *$ & $-1.919 * * *$ \\
\hline & $(0.115)$ & $(0.115)$ & $(0.115)$ & $(0.115)$ \\
\hline \multirow[t]{2}{*}{ Years separated from the military } & -0.019 & -0.018 & -0.018 & -0.019 \\
\hline & $(0.011)$ & $(0.011)$ & $(0.012)$ & $(0.011)$ \\
\hline \multirow[t]{2}{*}{ Length of service in the military } & 0.065 & 0.068 & 0.068 & 0.064 \\
\hline & $(0.041)$ & $(0.041)$ & $(0.041)$ & $(0.014)$ \\
\hline \multicolumn{5}{|l|}{ Era of Service (Ref. 75-90) } \\
\hline \multirow[t]{2}{*}{$55-64$} & $-2.746 * *$ & $-2.762 * *$ & $-2.764 * *$ & $-2.775 * *$ \\
\hline & $(1.056)$ & $(1.060)$ & (1.059) & $(1.060)$ \\
\hline
\end{tabular}


Table 7: OLS Regression of Household Income on Combat Veteran Status with Interaction Terms Cont.

\begin{tabular}{|c|c|c|c|c|}
\hline & M 1 & M 2 & M 3 & M 4 \\
\hline \multirow[t]{2}{*}{ Vietnam } & 0.018 & 0.020 & 0.240 & 0.020 \\
\hline & $(0.168)$ & $(0.168)$ & $(0.168)$ & $(0.168)$ \\
\hline \multirow[t]{2}{*}{$90-01$} & $0.379 *$ & $0.378 *$ & $0.378^{*}$ & $0.376^{*}$ \\
\hline & $(0.168)$ & $(0.168)$ & $(0.167)$ & $(0.167)$ \\
\hline \multirow[t]{2}{*}{ Post 9/11 } & 0.253 & 0.243 & 0.247 & 0.248 \\
\hline & $(0.234)$ & $(0.234)$ & $(0.234)$ & $(0.235)$ \\
\hline \multirow[t]{2}{*}{ Disability } & $-1.176 * * *$ & $-1.172 * * *$ & $-1.165 * * *$ & $-1.180 * * *$ \\
\hline & $(0.150)$ & $(0.150)$ & $(0.150)$ & $(0.150)$ \\
\hline \multirow[t]{2}{*}{ Household size } & $0.332 * * *$ & $0.333 * * *$ & $0.334 * * *$ & $0.331 * * *$ \\
\hline & $(0.044)$ & $(0.044)$ & $(0.044)$ & $(0.044)$ \\
\hline \multicolumn{5}{|l|}{ Interaction Effects } \\
\hline \multirow[t]{2}{*}{ Female Combat Veteran } & $-0.986 *$ & & & $-1.028^{*}$ \\
\hline & $(0.402)$ & & & $(0.403)$ \\
\hline \multirow[t]{2}{*}{ NHB Combat Veteran ${ }^{a}$} & & 0.259 & & 0.269 \\
\hline & & $(0.309)$ & & $(0.310)$ \\
\hline \multirow[t]{2}{*}{ HIS Combat Veteran ${ }^{\text {b }}$} & & -0.068 & & -0.105 \\
\hline & & $(0.414)$ & & $(0.414)$ \\
\hline \multirow[t]{2}{*}{ OTH Combat Veteran ${ }^{c}$} & & 0.272 & & 0.308 \\
\hline & & $(0.495)$ & & $(0.495)$ \\
\hline \multirow[t]{2}{*}{ Lt HS or HS Combat Veteran ${ }^{d}$} & & & -0.169 & -0.193 \\
\hline & & & $(0.215)$ & $(0.216)$ \\
\hline $\mathrm{R}^{2}$ & 0.2753 & 0.2744 & 0.2744 & 0.2756 \\
\hline Adj. $R^{2}$ & 0.2722 & 0.2709 & 0.2712 & 0.2718 \\
\hline
\end{tabular}

Source: Current Population Survey July 2010, Veterans Supplement. Note: Standard error in parentheses. $\mathrm{N}=4197$.

$* \mathrm{p}<.05 * * \mathrm{p}<.01 * * * \mathrm{p}<.001$

${ }^{a}$ Non-Hispanic Black, ${ }^{b}$ Hispanic, ${ }^{c}$ Other racial categories, ${ }^{d}$ Less than High school or High school 
Lastly, Model 4 of Table 7 shows the effects of all interaction terms at once. Again, the combat veteran coefficient is non-significant; the variables from previous models remain relatively unchanged. The female combat veteran coefficient is the only interaction term to be significant at $-1.028(p<.05)$ indicating a slightly higher negative impact on household income. This model accounts for $27.56 \%$ of the variation of the dependent variable as noted by the $\mathrm{R}^{2}$ term.

Table 7 provides similar results to the previous table. Again, very few differences between combat and non-combat veterans are seen. The one notable difference however appears with the introduction of the gender interaction term. In Models 1 and 4 female combat veterans are shown to have decreased levels of household income as compared to male non-combat veteran. 


\section{Discussion}

\section{The Effect of Veteran Status on Household Income}

The first research question of this study is: How does veteran status affect household income? It was hypothesized that veterans would have higher levels of household income than their non-veteran counterparts. This hypothesis received mixed support. After controlling for race, gender and education veteran status was not significantly related to income. As noted by the descriptive statistics in Table $2 b$, veterans are more likely to be male, non-Hispanic White, and to have higher levels of education as compared to non-veterans. Further noted in Table $2 \mathrm{~b}$ veterans are more likely to achieve higher levels of education, this finding contradicts the bulk of the literature which suggests that military service is negatively correlated with later educational attainment. However this manner of measuring educational attainment differs from its utilization in previous research. In previous studies education has been utilized as a continuous variable measuring the highest grade of schooling completed (Cooney et al. 2003; Teachman 2007; Teachman and Tedrow 2007), as an ordinal variable with few categories measuring different levels of education (Barley 1998; Kleykamp 2010; MacLean 2008; MacLean and Edwards 2010), and as a dichotomous variable measuring whether a respondent was a high school graduate or not (Hope et al. 2011). It may be the case that due to recent changes in the educational funding available for veterans that veterans are seeking out more education at increased rates. 
These results however, tell only a portion of the story. As will be shown, these statuses in race, gender, and education may not actually benefit veterans.

The second set of research questions of this project were: How does the effect of veteran status on household income differ by gender, race, and educational attainment? It was hypothesized that veteran women, racial and ethnic minorities, and those with low education would receive benefits from their military service which would manifest as higher levels of household income as compared to their non-veteran counterparts.

The first interaction term analyzed gender and veteran status. As expected, female non-veterans earned less than male non-veterans. However, unexpectedly, veterans of this sample earned similar levels of household income as compared to their similar non-veteran counterparts; the gender income disparity that exists for nonveterans remains for veterans. Past research has found that female veterans have higher levels of education and increased economic performance (Mehay and Hirsch 1996), that the gender advantage is present for only those with lower levels of education (Kogut et al. 2010), and conversely that female veterans tend to suffer an income disadvantage relative to female non-veterans (Cooney et al. 2003). Whether this finding regarding gender and veteran status is due to marital behaviors, education levels, or service related factors, these results add to the existing literature. 
Table 5 Model 2 displays the effect of veteran status when paired with race and ethnicity variables on household income. As expected, those veterans who are within the Non-Hispanic Black and Hispanic categories experience increased levels of household income when compared to similar non-veterans; conversely, Non-Hispanic White veterans experience a negative impact to household income. Figure 1 graphs the results of the coefficient equation for veteran status and race on household income.

Figure 1: Impact of Race and Veteran Status on Household Income

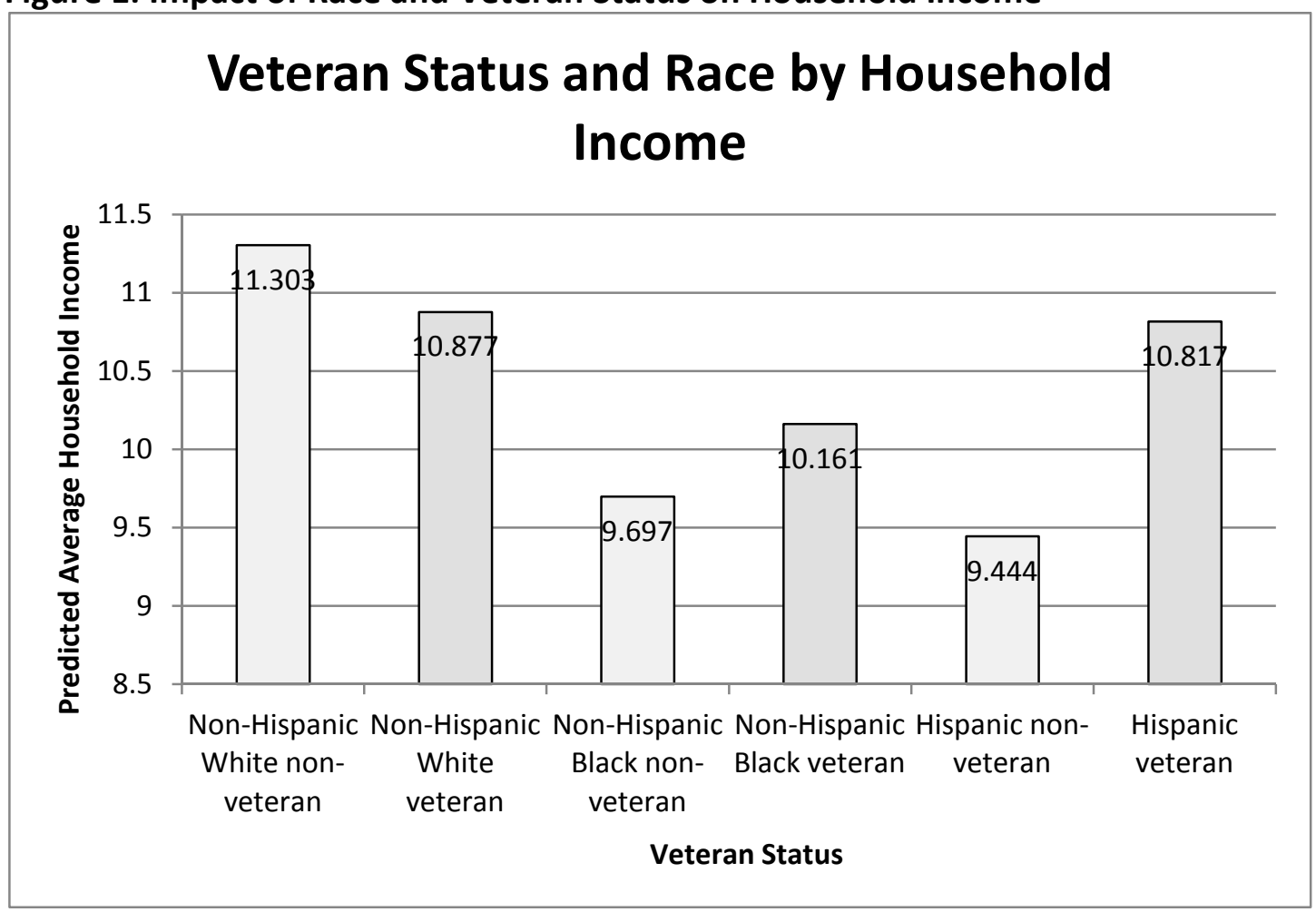

Immediately evident from the results in Figure 1, is that all veterans achieve lower levels of household income than non-Hispanic White non-veterans. For some racial minorities, veteran status offers a slight boost to economic performance that 
ultimately leads to higher levels of household income than would have otherwise been achieved. Conversely, non-Hispanic White veterans experience lower levels of household income as compared to their non-veteran counterparts. As the theory section has shown, racial minorities due to institutional and individual level racist practices have experienced a deficit in relevant capital. Regression results from this study regarding racial minority veteran economic performance further support the belief that the military imparts benefits to some of those who serve. These results support literature review findings which show in general that Hispanic and Black veterans receive income advantages as compared to their non-veteran counterparts (Browning et al. 1973, Teachman and Tedrow 2004, 2007). Furthermore, just as in this study, military service does not appear to be beneficial to a majority of White males (Teachman and Tedrow 2007). The capital received in the military may influence the minority's civilian choice of occupations following military service. Racial minority veterans may choose occupations in which their skills earned in the military are more applicable than non-minority veterans; minority veterans may also receive higher wages in the occupations that they choose.

As compared to similar non-veterans, veterans with lower educational attainment have higher household incomes while veterans with higher levels of educational attainment average lower household incomes. Figure 2 displays the levels of household income across veteran status and educational attainment. Veterans with lower educational 
attainment receive a premium to household income as compared to similar non-

veterans. Highly educated non-veterans earn the highest level of household income as compared to all other groups; highly educated veterans receive a household income disadvantage as compared to their non-veteran counterparts.

Figure 2: Impact of Veteran Status and Educational Attainment on household Income

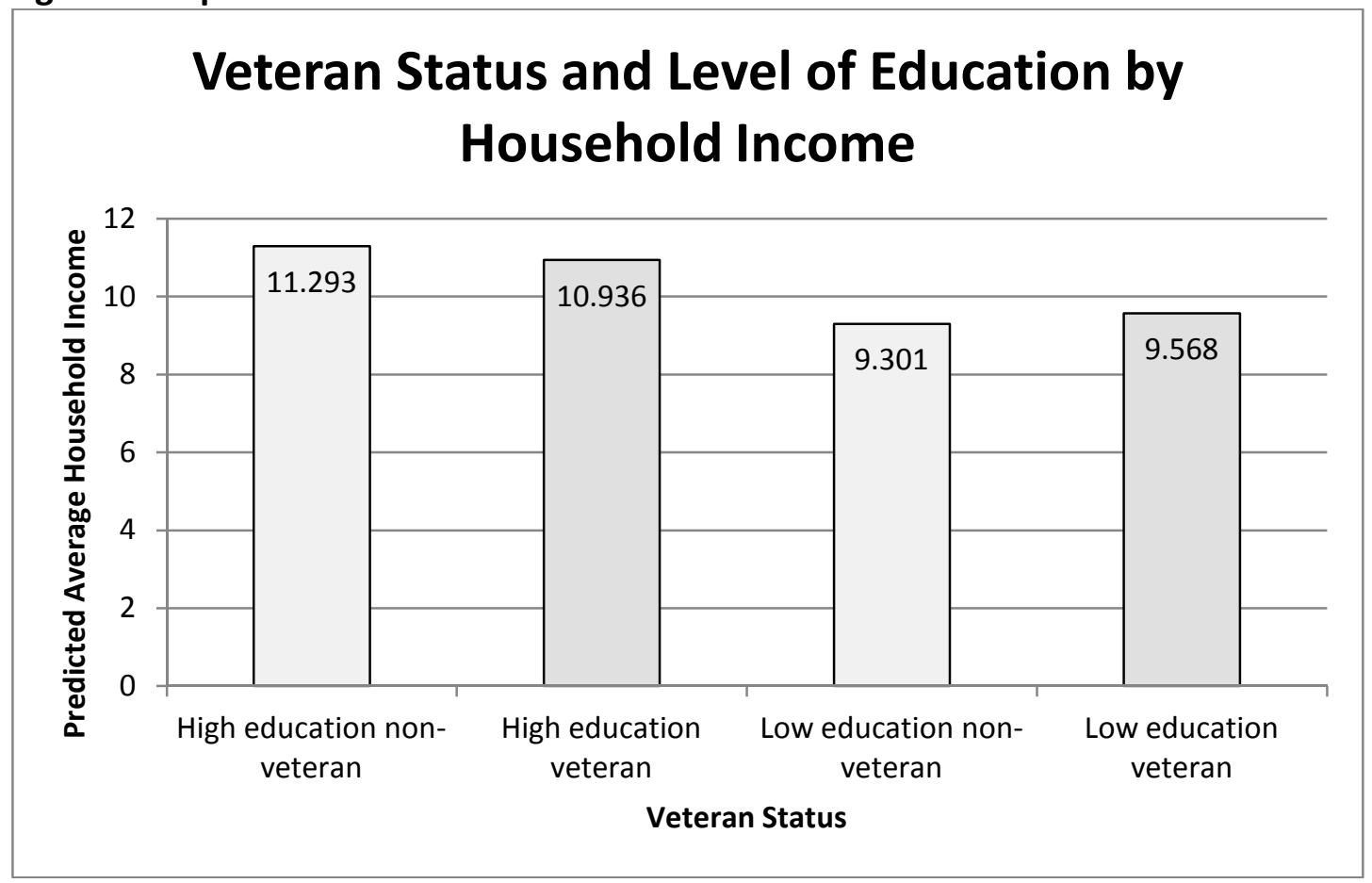

When considering the results from these analyses, utilizing the provided

theoretical lenses may offer some possible explanations. The positive performance of minorities and those with low education may be due to the "bridging environment" offered by the military services (Cooney et al. 2003). These normally disadvantaged veterans may receive access to human and social capital that would have otherwise been missed had they not served. Furthermore, civilian employers may value these 
minority and lower educated veterans more so than their non-veteran counterparts due to the legitimation offered by an honorable discharge from the military. Employers may be less likely to discriminate against those who have access to verification of honorable service in the military because these minority veterans have "proved themselves", especially those veterans from eras where service in the military is seen in a positive light. It must further be considered that the eras that veterans have served with have been accompanied by differing civilian economic activity. Where in the past veterans were greeted with an abundance of manufacturing occupations, occupations which may more readily apply to military experiences, veterans of recent conflicts may face an environment of occupations which have no relevance to the same experiences and skill sets.

These results support previous findings noted in the literature review. As has been shown, military training adds human capital which leads to the development of skills useful to the civilian sector (Cooney et al. 2003; Browing et al. 1973; Kleykamp 2009). Furthermore the military imparts characteristics which may be valuable to the civilian economic sector (Hope et al.2011; Kleykamp 2009; Teachman and Tedrow 2007). Because those with low education have increased levels of household income as compared to their non-veteran counterparts, the military may be imparting benefits to those who serve. 
These results differ slightly in that veterans have increased rates of higher levels of education as compared to non-veterans. As compared to non-veterans who have a low education proportion of $42.37 \%$, veterans have $33.45 \%$. This shows that veterans are more likely to obtain more than a high school education. Previous literature shows that those who serve in the military are less likely to have higher levels of education (Cohen, Segal, and Temme 1986; Cohen, Warner, and Segal 1995; MacLean 2005) and that service in the military has a negative correlation with later educational attainment (Teachman 2007).

However, military service does not provide enough of a boost on household income to overcome the deficits experienced outside of the military due to institutional and interpersonal level discrimination. As shown previously, women, minorities, and those with less education face lower levels of economic performance as compared to those who are men, non-Hispanic White, and those with high levels of education. Regardless of the benefits received, racial minority and low educationed veterans do not outperform non-Hispanic White male non-veteran in all models of this research.

Furthermore, non-Hispanic White and more educated veterans experience a negative impact on household income as compared to their non-veteran counterparts. This deficit may be experienced by all who serve and may be explained by the work of MacLean (2008) and Teachman and Tedrow (2007) which suggests that either the military acts as a disruption which interrupts the normal progression of personal 
economic development or that the military interferes with the development of economic relevant capital. It may be the case that the military disrupts the normative creation of civilian economic experience which leads to decreased levels of performance and earnings. Non-Hispanic White veterans, due to their service, may experience decreased levels of relevant economic capital due to their service; their privileged racial status may have offered them access to higher levels of capital outside of the military which is missed due to service. As noted earlier by Greendburg and Rosenheck (2007), White veterans, specifically Vietnam veterans, may be more likely to come from working class families with lower levels of education. This knowledge in itself may explain why those veterans with advantaged statuses receive lower levels of household income as compared to their non-veteran counterparts. Findings from this research support this. Veterans with higher levels of education may similarly miss out on important capital resources due to their service. However, it could be that this increased level of education took place following release from military service. If this is the case, increased levels of education may occur at a period late in the life course which may adversely affect occupational duration and hence earnings. Lastly, it may be the case that employers view veterans with demographics that generally receive preferential treatment negatively. It may be the case that the military is viewed as beneficial for racial minorities and those with low levels of education, but not as useful for White, 
more educated, or males. While this is unlikely, if it is true it may account for some of the negative performance of White, male, and higher educated veterans.

Initial findings from Figures 1 and 2 show that military service works to decrease disparity among veterans. Service in the military appears to decrease the wage disparity that exists in the civilian economic sphere; as noted in Figures 1 and 2 household income differences among veterans by race and education are smaller than those that exist between non-veterans. This simple finding lends support to the belief that the military is an egalitarian work environment which works to decrease the negative impact of normally disadvantaged statuses.

\section{Combat Veteran Status and Differences Among Veterans}

Despite the finding that military service decreases household income disparity, inequality still exists among those who serve in the military. As seen in Table 6, veterans have lower household income due to the statuses of Non-Hispanic Black, lower levels of education, being unmarried, being unemployed, and being disabled. Intuitively, the effects of being unmarried and unemployed should have a negative effect on household income regardless of military service. However, the negative effects of being NonHispanic Black and having lower levels of education are interesting. Although reduced relative to non-veterans, income disparities remain among veterans.

The sixth research question of this project was: What affect does combat status have on household income among veterans? It was hypothesized that combat veterans 
would receive a wage disadvantage as compared to non-combat veterans. Table 6 establishes a baseline of the experiences of veterans when considering household income. Table 7 begins with this baseline and adds to it the three interaction terms of interest in this study. Interestingly, combat veterans and veterans do not differ significantly when considering household income. Among veterans some statuses do appear to have a strong impact on the household income respondents report, these are: non-Hispanic Black, low educational attainment, unmarried, unemployed, and having a disability. These results are to be expected however, as findings in previous sections have shown the negative effects these statuses have on household income. It must be noted that, as seen in the descriptive statistics for the veteran sample, combat veterans are more likely to have a disability and are perhaps more likely to suffer from the negative effects of this situation.

Of the interaction terms, only one was significant. While male combat veterans and female veterans do not differ from the controls, female combat veterans experience a significant negative to household income as compared to non-veterans and male veterans. This result that female combat veterans are for some reason disadvantaged economically following their discharge from military service is surprising. According to the bridging hypothesis those who are disadvantaged economically prior to service should gain the most from military service. 
Murdoch et al. (2003) show that females were less likely than males to receive support from the VA following combat exposure. This delegitimation experienced by female combat veterans may make access to the VA or other agencies more difficult and thus may negatively impact their economic performance. This may explain why female combat veterans, the group to receive significant results, experience a negative impact on household income as compared to male non-combat veterans.

It may be the case that female combat veterans do not receive access to the relevant capital while in the military, however this is unlikely. It may be the case that females who serve in combat, due to capital building and experiences, may be less likely to follow societal gender roles. In some cases, breaking from societal gender roles may benefit female veterans in that they may work more and may seek out non-feminized occupations. Work in male typed occupations may increase discrimination which may negatively affect female combat veteran economic performance. Breaking from societal gender norms may increase stress which, coupled with an increased likelihood of disability due to combat experience may cause negative economic performance for female combat veterans.

Female combat veterans may also be less likely to marry. This finding is marginally supported by proportions from Table 8 : of female respondents $47 \%$ of nonveterans, $46 \%$ of non-combat veterans, and $47 \%$ of combat veterans are unmarried. It is easily apparent that remaining unmarried will negatively affect potential household 
earnings, especially for females who typically earn less than their male counterparts.

Overall it appears that, for veterans, experiencing combat does not produce a significant effect on household income.

It may further be noted that those with disabilities earn less in all models and tables in which the variable is present. As stated previously, having a disability is negatively associated with economic performance (Heflin et al 2011). Previous literature also shows that veteran status may alleviate negative problems experienced by disabilities (London et al. 2010). This research shows that even among veterans, having a disability has a strong negative effect on household income. It is unclear whether veteran status assuages these negative effects however. It must also be noted that combat veterans have a higher proportion of being disabled, $15.16 \%$ as compared to non-combat veterans at $12.03 \%$. This finding supports previous literature that combat exposure increases the likelihood of disability (MacLean 2010).

\section{Marriage Rates}

Table 8: Descriptive Statistics of Unmarried Respondents (weighted \%)

\begin{tabular}{|c|c|c|c|c|c|c|c|c|}
\hline & Female & Male & NHW & $\mathrm{NHB}$ & HIS & $\mathrm{OTH}$ & $\begin{array}{c}\text { High } \\
\text { Education }\end{array}$ & $\begin{array}{c}\text { Low } \\
\text { Education }\end{array}$ \\
\hline non-veteran & $\begin{array}{c}19299 \\
(46.48)\end{array}$ & $\begin{array}{c}16822 \\
(47.36)\end{array}$ & $\begin{array}{c}23235 \\
(43.51)\end{array}$ & $\begin{array}{c}5245 \\
(66.83)\end{array}$ & $\begin{array}{c}4949 \\
(46.86)\end{array}$ & $\begin{array}{c}2695 \\
(43.82)\end{array}$ & $\begin{array}{c}19706 \\
(44.08)\end{array}$ & $\begin{array}{c}16415 \\
(50.72)\end{array}$ \\
\hline $\begin{array}{c}\text { non-combat } \\
\text { veteran }\end{array}$ & $\begin{array}{c}143 \\
(45.87)\end{array}$ & $\begin{array}{c}785 \\
(35.05)\end{array}$ & $\begin{array}{c}702 \\
(32.81)\end{array}$ & $\begin{array}{c}134 \\
(58.69)\end{array}$ & $\begin{array}{c}40 \\
(34.63)\end{array}$ & $\begin{array}{c}52 \\
(45.69)\end{array}$ & $\begin{array}{c}580 \\
(34.73)\end{array}$ & $\begin{array}{c}348 \\
(40.14)\end{array}$ \\
\hline $\begin{array}{l}\text { combat } \\
\text { veteran }\end{array}$ & $\begin{array}{c}35 \\
(46.85)\end{array}$ & $\begin{array}{c}451 \\
(33.73)\end{array}$ & $\begin{array}{c}360 \\
(31.76)\end{array}$ & $\begin{array}{c}68 \\
(44.43)\end{array}$ & $\begin{array}{c}30 \\
(45.56)\end{array}$ & $\begin{array}{c}28 \\
(35.34)\end{array}$ & $\begin{array}{c}324 \\
(33.81)\end{array}$ & $\begin{array}{c}162 \\
(35.71)\end{array}$ \\
\hline
\end{tabular}


Household income is partly determined by the marital practices of respondents. It is likely that those who are married are going to have higher levels of household income as compared to those who are unmarried. Table 8 provides the descriptive statistics of those who are unmarried, looking specifically at non-veterans, non-combat veterans, and combat veterans by the important demographic statuses identified in this project. When considering race and education, non-combat and combat veterans in most cases, excepting Other non-combat veterans, have lower chances of being unmarried as compared to non-veterans. Comparing these results with those of the previous interaction terms, there are contradictory results concerning the effects of being married. On one hand, low educated and racial minority veterans, who are more likely to be married, are receiving a premium to household income. Conversely, NonHispanic White and higher educated veterans, who are also more likely to be married, experience a disadvantage to household income as compared to their non-veteran counterparts. This same paradox continues when considering the interaction term of female combat veterans. In this case, female combat veterans are just as likely as female non-veterans and non-combat veterans to be married, but they experience a disadvantage to household income.

Because of the similar levels of being unmarried for women in this study, it is difficult to explain the negative levels of household income experienced by this group. 
However, this lack of marriage differences may speak to the effects of having served in the military. Female combat veterans may face difficulties other than marriage formation which impact their earnings. Overall, service in the military may lead one to seek out marriage and thus positively affect household income. Excepting gender, in most other situations racial minority and low educated combat and non-combat veterans are more likely to be married than their non-veteran counterparts; these same veterans with disadvantaged statuses also experience an increase to household income. However it must be said that for those in the categories of non-Hispanic White and higher levels of education experience increased rates of marriage but simultaneously do not experience a positive impact to household income as compared to their non-veteran counterparts. These last findings obscure the effects of marriage on household income for veterans. Clearly, the effects of military service on household income are not due solely to the marital practices of veterans.

\section{Excluded Respondents}

The primary differences existing between those included and those exclude in this study can be found in Table $2 \mathrm{a}$ and are discussed in previous sections. More specific differences may exist; however the interpretation of results changes little due to the following. The most notable difference existing between those who were included and those who were excluded is the average level of household income. The mean household income of non-veterans, veterans, and those not included are as follows: 
10.93 for non-veterans, 11.48 for veterans, and 7.37 for those not included. Those not included have lower levels of household income than those included. Therefore, the results from this study and the subsequent discussion may have less relevance when referring to those of lower economic performance; these results may overestimate the economic performance of those respondents not included. Excluded respondents further differed by gender with $38.2 \%$ reporting as female. While this is still greater than those included veterans, this proportion differs greatly from the non-veteran sample which is $54.46 \%$ female. Furthermore, those who are missing are less likely to be white and much more likely to belong to the Other racial category than both the Non-veteran and Veteran groups. As noted previously, those excluded tend to be those people who are not of working age, specifically those who are of retirement age, and therefore these results may not accurately represent their experiences.

\section{Occupation Sector, Veteran Status, and Demographics}

In Appendix A the descriptive statistics of occupational sector is shown in relation to veteran and the demographic statuses which are focused upon in this study. The total number of respondents in each category is listed followed by the weighted percentages; all results, within demographic categories, such as male gender, female gender, etc. are significant. For these analyses the category of Armed Forces was removed since it represented only 14 respondents. 
While differences between non-veterans and veterans are significant, the category of men experiences only slight differences. Conversely, more differences for women exist, namely, female veterans are more likely to be in Management, Professional and Related Occupations, Construction and Maintenance Occupations, and Production, Transportation and Material Moving Occupations. These differences are important to note, female veterans are more likely than their non-veteran counterparts to work in masculine typed fields which may be economically beneficial to their success. It is likely that the experience of military service, the alteration of the life course progression and capital earned while in the military, lead to this difference in occupational choices for female veterans. This may further account for the lack of differences which exists between female and male veteran families, and further the lack of differences between female veterans and non-veterans; the occupations they choose may partially account for a decrease in the wage disparity normally experienced by women.

Some notable differences appear when considering the education categories. Those high educated veterans are less likely to be in Management occupations and Sales occupations and they are more likely to be in Construction occupations and Production / Transportation occupations. These differences in occupations may account for the decreased earnings seen in previous regressions; high educated veterans may choose professions that pay less than other professions for their educational level. A similar 
trend is seen with low educated veterans. Low educated veterans are more likely to be in Management occupations, Construction occupations, and Production occupations and less likely to be in Service and Sales occupations. Where these choices may disadvantage high educated veterans, these positions may advantage low educated veterans as compared to their non-veteran counterparts. It may be the case that due to service in the military and the capital obtained, low educated veterans are positively viewed by employers and given premium wages as compared to similar non-veterans. It appears that service in the military may act to alter the normal career progression experienced by those with higher levels of education; high educated veterans may value Construction and Production occupations and thus may not achieve the higher levels of earnings that normally would be associated with their levels of education.

Lastly, race must be considered. Non-Hispanic White veterans are less likely to be in Management occupations, Sales occupations and are more likely to be in Construction occupations and Production occupations. These differences, again likely caused by the alteration to the normal life course of military service, may account for the lower levels of income experienced by non-Hispanic White veterans. Non-Hispanic Black and Hispanic veterans experienced similar increases to household earnings as shown in previous regression tables. Non-Hispanic Black veterans are more likely to be in Management occupations, Construction occupations, and Production occupations than their non-veteran counterparts. The increased earnings experienced Non-Hispanic 
Black veterans may be partially influenced by this decreased likelihood of being in Service and Sales occupational sectors. Hispanic veterans similarly are less likely to be in the Service and Sales occupational sectors. However they are much more likely than their non-veteran counterparts to be in Management occupations which may account for some of the large increase of household income that Hispanic veterans experience. Veterans of other racial categories are less likely to be in Management occupations and Sales occupations and more likely to be in Construction and Production occupations. Again, these are similar occupational choices as the two previous racial minority veteran groups. However these choices do not appear to benefit veterans of other racial categories since non-significant results were achieved in previous regression tables.

Regardless of the demographic group, veterans differ from their non-veteran counterparts. This does not necessitate that that difference is positive, not all veteran groups out perform their non-veteran counterparts. However what can be taken away from this is the understanding that the military is impacting the normal life progression of these people which is leading to career choices which differ from those who did not serve.

\section{Occupation Sector, Combat Veteran Status, and Demographics}

In Appendix B the descriptive statistics of occupational sector is shown in relation to combat veteran status and the demographic statuses which are focused upon in this study. The total number of respondents in each category is listed followed 
by the weighted percentages; only four demographic categories received significant results, namely the male gender, those with higher education, and those in the Hispanic and Other racial categories.

Male combat veterans are more likely to be in Service occupations and less likely to be in Management occupations. While regression results concerning the interaction between gender and combat veteran status were non-significant, these findings are interesting. It must be noted that male combat veterans are more likely to be in service sector occupations which have been noted to have the lowest wages in the U.S. economy. Experiencing combat may have a detrimental effect for some men which leads them to make differing occupational as compared to those who do not experience combat.

The demographic category of high education received very significant results. High educated combat veterans are less likely to be in Management occupations and are more likely to be in Service occupations, Construction occupations and Production occupations. Again, non-significant results were achieved in previous regressions regarding the interaction of education and combat veteran status. Again, there may be a negative impact on average earnings for those high educated combat veterans who work in the Service sector. The increase of combat veterans with higher levels of education in the Construction occupations seems counter-intuitive. However, the 
impact of being in a combat zone may alter the progression of the life course which may make these occupations more applicable or available to these combat veterans.

Hispanic and Other racial category combat veterans have similar occupational concentrations with significant results. Both groups are less likely to be in Management occupations, Service occupations, Sales occupations, and more likely to be in Farming occupations, Construction occupations, and for Other combat veterans, Production occupations. Again, non-significant results were achieved for interaction terms regarding these statuses.

As with veterans, it appears that having experienced a combat zone impacts later civilian occupational selection. However, few differences exist among the veteran / combat veteran groups as noted by previous regression tables. It may be the case then that other choices are being made that influence the economic performances of these groups. For instance, since combat veterans are more likely to experience disabilities than non-combat veterans, it should be the case that they experience a negative impact on earnings. Household income may not capture these differences. Furthermore, since combat veterans may be more likely to received financial assistance from the VA for disabilities, the earnings they report may be boosted and therefore differ little if at all from those who have not experienced a combat zone. 


\section{Conclusion}

It was the intent of this research project to show the effects of veteran status on household income. We are left with a mixed picture. In some cases, specifically for low education and racial minority veterans, military service appears to impart some form of benefits in terms of future increases in household income. In other cases such as for White and higher educated veterans and female combat veterans, we see that military service negatively affects household income. These results further illuminate the negative disadvantages faced by racial minorities, women, and those with lower levels of education within our society. Overall it appears that the military provides an environment in which previously disadvantaged people can achieve increased levels of economic performance in the form of household income. This increased performance for veterans leads to an overall decrease in income disparities among the veteran population. This fact alone suggests that the military should be further studied to identify the practices that lead to this outcome.

\section{Limitations of the Study}

According to Hirsch and Mehay (2003) the CPS provides a large veteran sample but does not provide insight into the extent of previous military experience or worker ability or preferences. For instance, compared to enlisted soldiers, officers generally 
come from families of higher socioeconomic standings (MacLean 2008). Research has shown that among veterans, it appears that economic performance of officer veterans tends to be greater than non-veterans while enlisted personnel perform the same as or lower than non-veterans (Hirsch and Mehay 2003; MacLean 2008). This limits the ability for an analysis of the CPS to account for selectivity found within the veteran and non-veteran populations. It may be that a certain type of person is more likely to volunteer for military service. Overall there may be some characteristics which influence economic performance in the civilian sector that attract people to serve in the military. Furthermore, the CPS does not account for differences that may exist among enlisted and commissioned veterans.

The female veteran sample size of 456 may be negatively influencing significance levels. This small sample size could negatively impact the generalizability of results to the larger female veteran population in the United States. However, the use of a standardized weight, should counteract the limitation of a small female veteran sample size. Due to the weight, significant results are much more likely. This fact, indicates that results achieved in this project are reliable and valid.

Utilizing household income as a dependent variable has its weaknesses as well. The variable of household income does not actually measure the individual performance level of respondents; it could be that veterans do not themselves perform well and instead manage to rely on others, large families or wealthy spouses, to provide for them 
financially. However, regardless of the personal earnings, the veteran may still benefit from these increased household earnings, thus justifying the use of the household income variable. Furthermore, the household income variable has an allocation rate of approximately $20 \%$ as noted by the CPS user guide. This indicates that not all respondents provided their household income; instead it was assigned to them from the responses of the head of household. This may allow for the possibility of false reporting, however it is unlikely that veterans and non-veterans differ in reporting habits.

According to Detray (1982) two possibilities for veterans exist when attempting to determine the causes of economic outcomes: 1 ) those who are healthy may be more likely to invest heavily in human capital and more likely to join or be accepted into the military, 2) conversely veterans could face low initial earnings in the civilian labor force with steeper increases in the civilian economy than non-veterans; this could be due to differing investment practices in various capitals by veterans as compared to nonveterans. Either any benefits from veteran status are actually attributed to health or fitness status, or veterans actually earn capital which helps them overcome a lack of civilian economic experience. This selection bias, which may exist, may be applicable when considering the results for veterans in general, and perhaps even female veterans; due to the limited number of female veterans involved they may not adequately represent the experiences of all female veterans. Furthermore, this selection bias may 
have a non-constant effect depending on the era of service. It may be the case that more heavy selection criteria are utilized in eras of smaller military cohort size, thus leading to more stringent limitations placed on those who serve. This may indicate that in eras of small military cohorts those who serve may be more likely, than those who serve in larger cohort eras, to have increased civilian economic performance regardless of their military service. This last point is somewhat controlled for with the inclusion of the era variables; the greater impact of this problem remains un-controlled for just as many other service related characteristics.

Regardless of the limitations listed above, this study still provides meaningful results. While particular differences in service characteristics cannot be teased out among the veteran sample by when using the Current Population Survey, many of the service characteristics that have been found to have a profound impact on income and wages have been included in this study. Furthermore, while the use of household income may not directly address the effect of veteran status on earnings there is still much to be learned from this study. Marriage practices and household size have been analyzed in this study. While veterans are more likely to be married, there does not appear to be a clear correlation between marital practices and earnings as noted by the varying effects in the previous regression tables. 


\section{Policy Implications}

Veterans often experience traumatic events which have the potential to cause life-long harm. Furthermore veterans may be removed from a civilian labor market which often does not recognize their training and skills. These facts place veterans as a vulnerable subgroup in the United States population. Efforts should be made by the military to further facilitate the transition of veterans from military service into civilian life. While the changes in educational assistance and health care availability have helped, more can be done. An effort should be made to ensure that the skills veterans receive in the military easily transfer to the civilian sector. While programs exist to assist in the creation of interview and resume building skills, service members should receive credentials for their time served. Further, steps must to be taken to ensure that female veterans, specifically those who experience combat, receive the same access to benefits that are available to male combat veterans. It should not be the case that female combat veterans are suffering more so than their male counterparts. Ultimately, because the military appears to diminish household income disparities among those who serve, special attention should be paid to the manner in which this organization functions in order that greater equality can be achieved in our society.

\section{Future Directions}

Future research is needed to discern further differences in the economic performance of veterans. While household income is a valuable measure of economic 
performance, it is only one such measure which offers a limited perspective.

Quantitative research regarding other economic measures is warranted to broaden this understand. Specifically a look into the occupational sectors, the employment status, the school attendance rates, and more will help to create a stronger understanding of the experiences of veterans. Furthermore, qualitative research is greatly needed to increase this understanding of why these economic experiences exist and what actual effects they have on the lives of veterans. In-depth interviews regarding the experiences of both combat and non-combat veterans could shed light into the effects of military service on their lives. It is the hope of this researcher to obtain a greater understanding of the experiences of veterans in the hopes of further informing the policy decision making process. 


\section{Works Cited}

Alwin, Duane. 2012. "Integrating Varieties of Life Course Concepts." The Journals of Gerontology, Series B: Psychological Sciences and Social Sciences, 67(2), 206-220, doi:10.1093/geronb/gbr146.

Angrist, Joshua and Krueger, Alan. 1994. "Why Do World War II Veterans Earn More than Nonveterans?" Journal of Labor Economics 12:74-97.

Barley, Stephen. 1998. "Military Downsizing and the Career Prospects of Youth." Annals of the American Academy of Political and Social Science 559: 141-157.

Bourdieu, Pierre. 1986. "The Forms of Capital." Pp. 241-258 in Handbook of Theory and Research for the Sociology of Education. New York: Greenwood.

Belmont Philip, Schoenfeld Andrew, and Goodman Gens. 2010. "Epidemiology of Combat Wounds in Operation Iraqi Freedom and Operation Enduring Freedom: Orthopaedic Burden of Disease." Journal Of Surgical Orthopaedic Advances 2010.

Beusse, William E., Air Force Human Resources Laboratory, \& United States. 1974. The Impact Of Military Service On Low Aptitude Men. Alexandria, Va: Air Force Human Resources Laboratory (AFSC).

Blau, Francine and Kahn, Lawrence. 2006. "The Gender Pay Gap: Going, Going... But Not Gone" Pp. 37-66 in The Declining Significance of Gender? Edited by F. Blau, M. Brinton, and D. Grusky. New York: Russell Sage Foundation.

Blau Francine, Brinton Mary, and Kahn Lawrence. 2006. "The Declining Significance of Gender?" Pp. 3-34 in The Declining Significance of Gender? Edited by F. Blau, M. Brinton, and D. Grusky. New York: Russell Sage Foundation. 
Browning Harley, Lopreato Sally and Poston Dudley Jr. 1973. "Income and Veteran Status: Variations Among Mexican Americans, Blacks and Anglos". American Sociological Review Vol. 38, No. 1 (Feb., 1973), pp. 74-85. Retrieved from http://www.jstor.org/stable/2094332 on 30 Jan 12.

Bureau of Labor and Statistics. 2011. Employment Situation of Veterans - 2010. Mar 11. Retrieved 01 Feb 2010. (http://www.bls.gov/cps/)

Charles, Maria and Grusky, David. 2004. "Egalitarianism and Gender Inequality." Pp. 327-342 in The Declining Significance of Gender? Edited by F. Blau, M. Brinton, and D. Grusky. New York: Russell Sage Foundation.

Cohen Jere, Segal David, and Temme Lloyd. 1986. "The Educational Cost of Military Service in the 1960s". Journal of Political and Military Sociology, 14(Fall), 303-319.

Cohen Jere, Warner Rebecca, and Segal David. 1995. "Military Service and Educational Attainment in the All-Volunteer Force." Social Science Quarterly 76 :88-104. Retrieved from http://web.ebscohost.com/ehost/pdfviewer/pdfviewer?sid=95ec25ad-fe1d-49c9be6b-c620978ffb02\%40sessionmgr104\&vid=2\&hid=111 on 15 Jan 12.

Cohn, Samuel. 2000. Race and Gender Discrimination at Work. Boulder, Co.: Westview Press.

Cooney Richard, Segal Mady Jr., Segal David, and Falk William. 2003. "Racial Differences in the Impact of Military Service on the Socioeconomic Status of Women Veterans". Armed Forces \& Society 30:53

Daula Thomas, Smith D. A., and Nord Roy. 1990. "Inequality In The Military: Fact Or Fiction?". American Sociological Review 55, 714-718.

Davis, Kingsley and Moore, Wilbert. 1945. "Some Principles of Stratification." Pp. 14-17 in The Inequality Reader. Edited by D. Grusky and S. Szelenyi. Boulder, CO: Westview Press.

DeTray, Dennis 1982. "Veteran Status as a Screening Device". The American economic review (0002-8282), 72 (1). Retrieved from http://web.ebscohost.com.proxy.lib.pdx.edu/ehost/detail?sid=efff0026-a63c-46f0-a58fa2037b868d86\%40sessionmgr111\&vid=1\&hid=107\&bdata=JnNpdGU9ZWhvc3QtbGI2ZQ \%3d\%3d\#db=buh\&AN=4504979 on 15 Mar 2012. 
Erebes Christopher, Kaler Matthew, Schult Tamara, Polusny Melissa, and Arbisi Paul. 2011. "Mental health diagnosis and occupational functioning in National Guard/Reserve veterans returning from Iraq". Journal of Rehabilitation Research and Development 48 (10); 1159-1170.

Fischer Claude, Hout Michael, Jankowski Martin, Lucas Samuel, Swidler Ann, and Voss Kim. 1996. "Inequality by Design." Pp. 18-22 in The Inequality Reader. Edited by D. Grusky and S. Szelenyi. Boulder, CO: Westview Press.

Fitzgerald, Kelly. 2006. "The Effect of Military Service on Wealth Accumulation." Research on Aging 28:56 DOI: 10.1177/0164027505281574

Gamoran, Adam. 2001. "Schooling and Educational Inequality: A Forecast for the $21^{\text {st }}$ Century." Sociology of Education 74(EI): 135-153

Ginzburg Karni, Ein-Dor Tsachi, and Solomon Zahava. 2010. "Comorbidity of posttraumatic stress disorder, anxiety and depression: A 20-year longitudinal study of war veterans." Journal of Affective Disorders 123: 249-257.

Greenberg, Greg and Rosenheck, Robert. 2007. "Are Male Veterans at Greater Risk for Nonemployment than Nonveterans?" Monthly Labor Review, 23-31.

Heflin Colleen, Wilmoth Janet, and London Andrew. 2011. National Poverty Center Working Paper Series April 2011 "Veteran Status and Material Hardship?: The Moderating Influence of Disability" Janet M . Wilmoth Syracuse University. Health (San Francisco).

Hirsch, Barry and Mehay, Stephen. 2003. "Evaluating the Labor Market Performance of Veterans Using a Matched Comparison Group Design". The Journal of Human Resources XXXVIII

Hisnanick, John. 2003. "A Great Place to Start: The Role of Military Service on Human Capital Formation". Labour 17 (1) 25-45 (2003)

Hochschild, Arlie. 1997. "The Time Bind; When Work Becomes Home and Home Becomes Work." Pp. 284-289 in The Inequality Reader. Edited by D. Grusky and S. Szelenyi. Boulder, CO: Westview Press. 
Hoge Charles, Castro Carl, Messer Stephen, McGurk Dennis, Cotting Dave, and Koffman Robert. 2004. "Combat Duty in Iraq and Afghanistan, Mental Health Problems, and Barriers to Care." The New England Journal of Medicine 351: 13-22.

Hope John B., Oh Brian, and Mackin Patrick C. 2011. "Factors Affecting Entrepreneurship among Veterans". SBA Office of Advocacy. Retrieved 11 Feb 2012, from www.sba.gov/advocacy/808/15428

King Daniel, Taft Casey, King Lynda, Hammond Charity, and Stone Erika. 2006.

"Directionality of the Association Between Social Support and Posttraumatic Stress Disorder: A Longitudinal Investigation." Journal of Applied Social Psychology 36: 29802992.

Kleykamp, Meredith. 2009. "A Great Place to Start? : The Effect of Prior Military Service on Hiring". Armed Forces \& Society 35: 266. Retrieved 2 Feb 2012

(http://afs.sagepub.com/content/35/2/266)

Kleykamp, Meredith. 2010. "Where Did All the Soldiers Go? The effects of military downsizing on college enrollment and employment". Social Science Review 39: 477-490. Retrieved 2 Feb 2012

http://www.sciencedirect.com/science/article/pii/S0049089X09001045)

Kogut Carl, Short Larry, and Wall Jerry. 2010. "Estimating the Increase In Wages From Military Service". Journal of Economics and Economic Education Research, Volume 11, Number 2.

Krueger, Alan. 2003. "Inequality, Too Much of a Good Thing." Pp. 23-31 in The Inequality Reader. Edited by D. Grusky and S. Szelenyi. Boulder, CO: Westview Press.

Little, Roger and Fredland J. E., 1979. "Veteran Status, Earnings, And Race: Some Long Term Results". Armed Forces and Society 5, 244-260. Retrieved 2 Feb 2012 (http://afs.sagepub.com/content/5/2/244.short) London Andrew, Helfin Colleen, and Wilmoth Janet. 2011. National Poverty Center Working Paper Series April 2011 "Work-Related Disability, Veteran Status, and Poverty?: Implications for Family Well-Being." Syracuse University. Health (San Francisco). 
Lopreato, Sally and Poston, Dudley. 1977. “Differences In Earnings And Earnings Ability Between Black Veterans And Nonveterans In The United States". Social Science Quarterly 57, 759-766.

Lorber, Judith. 1994. "The Social Construction of Gender." Pp. 276-283 in The Inequality Reader. Edited by D. Grusky and S. Szelenyi. Boulder, CO: Westview Press.

MacLean, Alair. 2005. "Lessons from the Cold War: Military Service and College Education". Sociology of Education Vol. 78, No. 3 pp. 250-266. Retreived 4 Feb 2012 (http://www.jstor.org/stable/4148917)

MacLean, Alair. 2008. "The Cold War and Modern Memory: Veterans Reflect On Military Service". Journal of Political and Military Sociology Vol. 36, No. 1 (Summer): 103-130.

MacLean, Alair. 2010. "The Things They Carry: Combat, Disability and Unemployment among US Men." American sociological review, 75(4), 563-585.

doi:10.1177/0003122410374085

MacLean, Alair. 2011. "The Stratification of Military Service and Combat Exposure, 19341994." Social Science Research, 40(1), 336-348. doi:10.1016/j.ssresearch.2010.04.006

MacLean, Alair and Edwards, Ryan. 2009. "The Pervasive Role of Rank in the Health of U.S. Veterans". Armed Forces and Society 36; 765-785. Retrieved 02 Apr 2012 (http://afs.sagepub.com/content/36/5/765)

MacLean, Alair, and Parsons, Nicholas. 2010. "Unequal Risk: Combat Occupations in the Volunteer Military." Sociological Perspectives, 53(3), 347-372.

doi:10.1525/sop.2010.53.3.347.

Martindale, Melanie, Poston Dudley. 1979. "Variations In Veteran / Nonveteran Earnings Patterns Among WWII, Korea, And Vietnam War Cohorts". Armed Forces and Society 5, 219-243.

Massey, Douglas and Denton, Nancy. 1993. "American Apartheid, Segregation and the Making of the Underclass." Pp. 153-164 in The Inequality Reader. Edited by D. Grusky and S. Szelenyi. Boulder, CO: Westview Press. 
Mehay, Stephen and Hirsch, Barry. 1996. "The Post Military Earnings of Female Veterans". Industrial Relations 35 (2).

Meier, Kenneth, Stewart, Joseph and England, Robert. 1989. Race, Class, and Education: The politics of second-generation discrimination. Madison, Wis: University of Wisconsin Press.

Mirowsky, John. 1999. "Analyzing Associations between Mental Health and Social Circumstances". Pp. 105-123 in Handbook of the Sociology of Mental Health. Edited by C. S. Aneshensel and J. C. Phelan. New York: Kluwer Academic / Plenum Publishers.

Murdoch Maureen, Hodges James, Hunt Carolyn, Cowper Diane, Kressin Nancy, and O'Brien Nancy. 2003. "Gender Differences in Service Connection for PTSD." Medical Care 41 No. 8; 950-961. Retrieved 18 Feb 2013 from http://www.jstor.org/stable/3768090.

Oliver, Melvin and Shapiro, Thomas. 1997. "Black Wealth / White Wealth: A New Perspective on Racial Inequality." Pp. 258-265 in The Inequality Reader. Edited by D. Grusky and S. Szelenyi. Boulder, CO: Westview Press.

Omi, Michael and Winant, Howard. 1994. "Racial Formation in the United States, From the 1960s to the 1990s." Pp. 197-207 in The Inequality Reader. Edited by D. Grusky and S. Szelenyi. Boulder, CO: Westview Press.

Polachek, Solomon. 2006. "How the Life-cycle Human-capital Model Explains why the Gender Wage Gap Narrowed." Pp. 102-124 in The Declining Significance of Gender? Edited by F. Blau, M. Brinton, and D. Grusky. New York: Russell Sage Foundation. Renaud, Edwin. 2008. "The Attachment Characteristics of Combat Veterans with PTSD." Traumatology 14:1 - 12. DOI: 10.1177/1534765608319085

Reskin, Barbara. 1991. "Labor Markets as Queues, A Structural Approach to Changing Occupational Sex Composition." Pp. 315-326 in The Inequality Reader. Edited by D. Grusky and S. Szelenyi. Boulder, CO: Westview Press.

Sampson, Robert and Laub, John. 1996. "Socioeconomic Achievement In The Life Course Of Disadvantaged Men: Military Service As A Turning Point, Circa 1940-1965". American Sociological Review 61, 347-367. Retrieve 15 Dec 11 (http://www.jstor.org/stable/10.2307/2096353) 
Seeborg, Michael, 1994. "Race, Poverty And Enlistment: Some Evidence From The National Longitudinal Survey Of Youth". The Journal of Economics 20, 15-24. Retrieved 10 Dec 11 (http://works.bepress.com/michael_seeborg/8/)

Teachman, Jay. 2004. "Military Service During the Vietnam Era: Were There Consequences for Subsequent Civilian Earnings?". Social Forces 83(2); 709-730.

Teachman, Jay. 2007. "Military Service and Educational Attainment in the All-Volunteer Era". Sociology of Education Vol. 80, No. 4 pp. 359-374 Retreived 30 Jan 12 (http://www.jstor.org/stable/20452717)

Teachman, Jay. 2011. "Are Veterans Healthier? Military Service and Health at Age 40 in the All-Volunteer Era." Social Science Research, 40(1), 326-335.

doi:10.1016/j.ssresearch.2010.04.009

Teachman, Jay and Tedrow, Lucky. 2004. "Wages, Earnings, And Occupational Status: Did World War II Veterans Receive A Premium?". Social Science Research 33; 581-605 Retrieved 16 December 2011 (http://www.sciencedirect.com/science/article/pii/S0049089X03000838)

Teachman, Jay and Tedrow, Lucky. 2007. "Joining up: Did military service in the early all volunteer era affect subsequent civilian income?”. Social Science Research 36 ; pp. 1447-1474

Teachman, Jay and Tedrow, Lucky. 2008. "Divorce, Race, and Military Service: More than Equal Pay and Equal Opportunity." Journal of Marriage and Family, 70(November), 1030-1044. Retrieved from http://onlinelibrary.wiley.com/doi/10.1111/j.17413737.2008.00544.x/full

Codebook. United States Department of Commerce Bureau of the Census, United States Department of Labor Bureau of Labor Statistics, and United States Department of Veterans Affairs. 2010. Current Population Survey, July 2010: Veterans Supplement Codebook. Inter-university Consortium for Political and Social Research. Ann Arbor: Michigan. Retrieved 01 Jan 2012 (www.icpsr.umich.edu/)

User guide. United States Department of Commerce Bureau of the Census, United States Department of Labor Bureau of Labor Statistics, and United States Department of Veterans Affairs. 2010. Current Population Survey, July 2010: Veterans Supplement User 
Guide. Inter-university Consortium for Political and Social Research. Ann Arbor: Michigan. Retrieved 01 Jan 2012 (www.icpsr.umich.edu/)

Williams, David and Williams-Morris, Ruth. 2000. "Racism and Mental Health: the African American experience." Ethnicity and Health 5:243-268.

Wilcox, Sherrie. 2010. "Social Relationships and PTSD Symptomatology in Combat Veterans." Psychological Trauma: Theory, Research, Practice, and Policy 2(3): 175-182

Wilson, William. 1978. "The Declining Significance of Race, Blacks and Changing American Institutions." Pp. 225-245 in The Inequality Reader. Edited by D. Grusky and S. Szelenyi. Boulder, CO: Westview Press.

Wright, Erik O. 1979. Class structure and income determination. New York: Academic Press.

Wright, Erik O. 1997. Class counts, comparative studies in class analysis. Cambridge University Press UK.

Wright, Erik O. 2005. Approaches to class analysis. Cambridge, UK: Cambridge University Press. 


\section{Appendix A}

Occupational Frequencies by Veteran and Demographic Statuses (weighted \%)

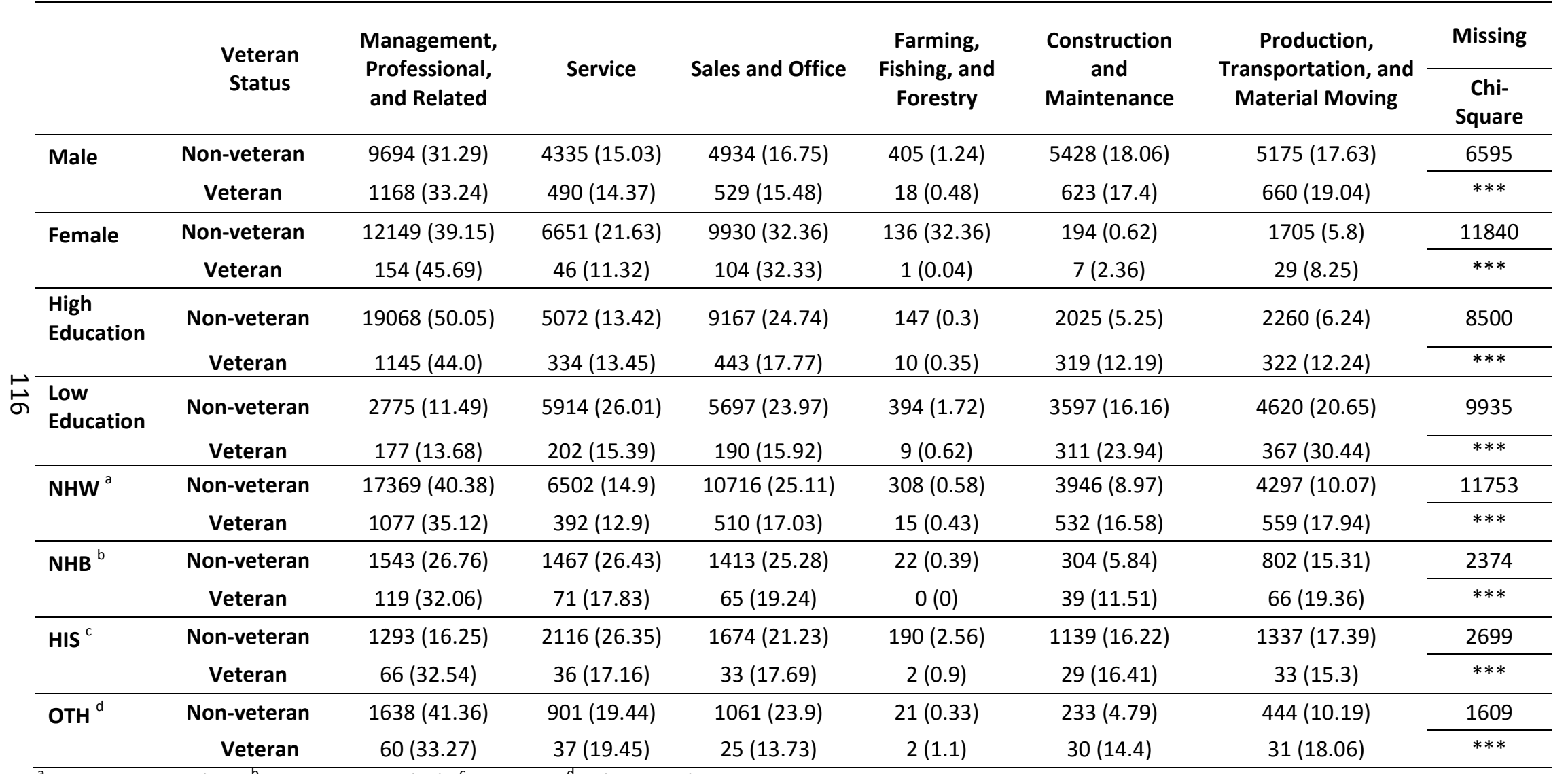

${ }^{\mathrm{a}}$ Non-Hispanic White, ${ }^{\mathrm{b}}$ Non-Hispanic Black, ${ }^{\mathrm{c}}$ Hispanic, ${ }^{\mathrm{d}}$ Other racial categories

$* \mathrm{p}<.05 * * \mathrm{p}<.01 * * * \mathrm{p}<.001$ 


\section{Appendix B}

Occupational Frequencies by Combat Veteran and Demographic Statuses (weighted \%)

\begin{tabular}{|c|c|c|c|c|c|c|c|c|}
\hline & Veteran Status & $\begin{array}{c}\text { Management, } \\
\text { Professional, and } \\
\text { Related }\end{array}$ & Service & $\begin{array}{c}\text { Sales and } \\
\text { Office }\end{array}$ & $\begin{array}{l}\text { Farming, } \\
\text { Fishing, and } \\
\text { Forestry }\end{array}$ & $\begin{array}{l}\text { Construction } \\
\text { and } \\
\text { Maintenance }\end{array}$ & $\begin{array}{c}\text { Production, } \\
\text { Transportation, } \\
\text { and Material } \\
\text { Moving }\end{array}$ & $\begin{array}{c}\text { Missing } \\
\text { Chi- } \\
\text { Square }\end{array}$ \\
\hline \multirow[t]{2}{*}{ Male } & Non-combat veteran & $668(35.12)$ & $248(12.84)$ & $279(15.26)$ & $9(0.41)$ & $350(17.48)$ & $368(18.89)$ & 872 \\
\hline & Combat veteran & $330(31.62)$ & $155(16.16)$ & $158(15.73)$ & $7(0.75)$ & 181 (17.69) & $178(18.05)$ & $*$ \\
\hline \multirow[t]{2}{*}{ Female } & Non-combat veteran & $109(46.02)$ & $32(11.48)$ & $70(29.88)$ & $1(0.06)$ & $5(2.65)$ & $24(9.9)$ & 102 \\
\hline & Combat veteran & $20(38.28)$ & $7(10.00)$ & $19(43.47)$ & $0(0)$ & $2(3.61)$ & $3(4.67)$ & \\
\hline \multirow[t]{2}{*}{$\begin{array}{l}\text { High } \\
\text { Education }\end{array}$} & Non-combat veteran & 685 (46.95) & $176(12.42)$ & $238(17.46)$ & $5(0.16)$ & $164(11.03)$ & 185 (11.99) & 585 \\
\hline & Combat veteran & 301 (39.46) & 105 (15.17) & $127(17.32)$ & $4(0.76)$ & $110(15.05)$ & $87(12.23)$ & $* * *$ \\
\hline \multirow[t]{2}{*}{$\begin{array}{l}\text { Low } \\
\text { Education }\end{array}$} & Non-combat veteran & $92(13.23)$ & $104(13.24)$ & $111(16.30)$ & $5(0.82)$ & $191(25.82)$ & 207 (30.59) & 389 \\
\hline & Combat veteran & $49(13.86)$ & $57(17.40)$ & $50(17.05)$ & $3(0.58)$ & $73(21.47)$ & $94(29.65)$ & \\
\hline \multirow[t]{2}{*}{$\mathrm{NHW}^{\mathrm{a}}$} & Non-combat veteran & $644(36.64)$ & $209(11.56)$ & $285(16.76)$ & $10(0.47)$ & $308(16.61)$ & $329(17.97)$ & 207 \\
\hline & Combat veteran & $288(33.77)$ & $118(14.93)$ & $142(16.95)$ & $4(0.55)$ & $151(17.01)$ & $141(16.80)$ & \\
\hline \multirow[t]{2}{*}{$\mathrm{NHB}^{\mathrm{b}}$} & Non-combat veteran & $72(37.48)$ & $32(14.5)$ & $29(17.63)$ & $0(0)$ & $19(10.55)$ & 34 (19.99) & 863 \\
\hline & Combat veteran & $30(29.18)$ & $25(21.97)$ & $19(19.57)$ & $0(0)$ & $10(10.23)$ & 19 (19.05) & \\
\hline \multirow[t]{2}{*}{ HIS $^{c}$} & Non-combat veteran & $32(35.71)$ & $18(18.49)$ & $20(20.71)$ & $0(0)$ & $11(12.11)$ & $13(12.98)$ & 935 \\
\hline & Combat veteran & $16(21.78)$ & $12(17.52)$ & $10(19.43)$ & $2(3.11)$ & $13(26.94)$ & $9(11.20)$ & $* *$ \\
\hline \multirow[t]{2}{*}{ OTH $^{d}$} & Non-combat veteran & $29(31.63)$ & $21(21.62)$ & $15(16.91)$ & $0(0)$ & 17 (15.49) & $16(14.36)$ & 917 \\
\hline & Combat veteran & $16(24.17)$ & $7(12.1)$ & $6(12.55)$ & $1(1.63)$ & $9(17.75)$ & $12(31.80)$ & $*$ \\
\hline
\end{tabular}

${ }^{\mathrm{a}}$ Non-Hispanic White, ${ }^{\mathrm{b}}$ Non-Hispanic Black, ${ }^{\mathrm{c}}$ Hispanic, ${ }^{\mathrm{d}}$ Other racial categories

$* \mathrm{p}<.05 * * \mathrm{p}<.01 * * * \mathrm{p}<.001$ 